\title{
¿Es posible medir el capital de movilidad para evaluar sus diferenciaciones sociodemográfica e intraurbana? El caso de los habitantes del Área Metropolitana de Santiago de Chile*
}

\author{
Daniel Delaunay** \\ Jean-Marc Fournier*** \\ Yasna Contreras $* * * *$
}

Es notoria la dificultad para discernir las desigualdades frente a la movilidad basándose únicamente en la intensidad, distancia o duración de los desplazamientos, o incluso en comportamientos que, a pesar de sus similitudes, no reflejan necesariamente una igualdad en los márgenes de maniobra que están a disposición de los individuos. Al considerar la diferenciación del capital de movilidad se abre la puerta a una realidad más compleja que replantea la importancia del sujeto social, sus trayectorias y sus capacidades. La ventaja heurística reside en la posibilidad de comparar la movilidad potencial y la movilidad efectiva.

En este trabajo se pretende dar una realidad estadística a la noción de "capital de movilidad" con base en una encuesta cuantitativa que se llevó a cabo en Santiago de Chile en el año 2009. La apreciación empírica de este capital se divide en varias proposiciones experimentales que luego se comparan con las características demo-económicas de los habitantes y su localización en la ciudad. De este modo se propone un enfoque demo-geográfico de un concepto sociológico.

Palabras clave: Santiago de Chile, movilidad urbana, capital de movilidad, desigualdades demo-económicas.

Fecha de recepción: 19 de agosto de 2011.

Fecha de aceptación: 8 de mayo de 2012.

* Este trabajo forma parte del programa de cooperación franco-chileno ECOS núm. C10H02 (2011-2013), dedicado al estudio de la movilidad en Santiago de Chile. Traducido del francés por José Israel Arreola Rodríguez.

** Director de Investigación en el Instituto de Investigación para el Desarrollo (IRD). Su laboratorio es UMR 201 "Desarrollo y sociedades" de la Universidad de París 1 Panthéon-Sorbonne y el IRD. Correo electrónico: <daniel.delaunay@ird.fr>.

*** Geógrafo; profesor de la Universidad de Caen. Correo electrónico: <jean-marc. fournier@unicaen.fr>.

**** Geógrafa; profesora asistente de Geografía, Universidad de Chile. Correo electrónico:<ycontrerasg@uchilefau.cl>.

ESTUDIOS DEMOGRÁFICOS Y URBANOS, VOL. 28, NÚM. 1 (82), 2013, 9-51 
Is It Possible to Measure Capital Mobility to Assess its Sociodemographic and Intraurban Differentiations? The Case of the Inhabitants of the Metropolitan Area of Santiago de Chile

It is notoriously difficult to discern inequalities regarding mobility solely on the basis of the intensity, distance or duration of displacements, or even behaviors which, despite their similarities, do not necessarily reflect equality in the scope for maneuver available to individuals. Considering the distinctions between capital mobility opens the door to a more complex reality which reappraises the importance of social subjects, their careers and capabilities. The heuristic advantage lies in the possibility of comparing potential and effective mobility.

This paper seeks to lend statistical reality to the notion of "capital of mobility" based on a quantitative survey undertaken in Santiago de Chile in 2009. The empirical assessment of this capital of mobility divided into several experimental proposals which are then compared with the demo-economic characteristics of the inhabitants and their location in the city. A demo-geographic approach is thereby proposed from a sociological concept.

Key words: Santiago de Chile, urban mobility, capital of mobility, demo-economic inequalities.

La tensión entre la coacción para la movilidad y los costos individuales y colectivos que implica hace necesaria una revisión de las recomendaciones conceptuales y políticas. En la literatura reciente el debate se traslada hacia el acceso a la movilidad y la capacidad de los individuos de instrumentarla sin necesariamente practicarla. Poseer capital de movilidad en reserva, siendo distintivo, se convertiría en una virtud. Tanto el nuevo ideal como el concepto de capital de movilidad encontrarían su fundamentación en múltiples dimensiones económicas, cognitivas y organizativas, pero no están respaldadas por una verdadera comprobación empírica y menos aún estadística. ¿Sería su relevancia de orden operativo para el análisis de casos concretos? ¿Es pertinente su inclusión en una encuesta estadística? La legitimidad de esta idea se basa en un consenso general: una simple medición de la frecuencia o de la duración de los desplazamientos no establece por sí sola la desigualdad de los individuos frente al recurso de la movilidad. Una misma práctica puede esconder dos estrategias opuestas entre las cuales no se puede saber cuál es la que discrimina, la que es preferible. En comparación, la idea de capital, que presupone la acumulación de experiencia y de capacidad para asociar diferentes formas de movilidad, 
desvanece en parte las reservas que suscita la práctica por sí sola. Al considerar la diferenciación del capital de movilidad se abre la puerta a una realidad más compleja que replantea la importancia del sujeto social, de sus trayectorias y de sus capacidades. La ventaja heurística reside en la posibilidad de comparar la movilidad potencial y la movilidad efectiva, y encontrar de este modo el sentido y los fundamentos de determinadas elecciones.

En este trabajo se pretende, en primer lugar, dar justamente una realidad estadística a la noción de "capital de movilidad" con base en una encuesta que se llevó a cabo en Santiago de Chile en 2009. ${ }^{1}$ El ejercicio supone la definición de sus límites y sus componentes para aplicarlos en seguida a los datos que proporciona la encuesta, y por otra parte, la concepción de un método para compararlos con las prácticas observadas. Para esto se compararán y definirán de manera independiente tres conjuntos de estadísticas para evitar las validaciones tautológicas: índices o características del capital de movilidad, medidas de movilidad residencial y cotidiana, variables de control para dominar las variaciones universales de la movilidad (tal como la etapa en el ciclo de vida) o las discriminaciones (tal como el género). Las conclusiones del análisis valorado en cifras se confrontarán con los testimonios de los citadinos y se contextualizarán en algunos barrios del área metropolitana que fueron seleccionados por la encuesta, aprovechando así la complementariedad de los datos cuantitativos y la observación cualitativa de los discursos de los habitantes de las zonas encuestadas.

\section{El capital de movilidad: un concepto emergente y exploratorio}

Actualmente las nociones de capital humano, capital social, capital cultural y capital simbólico se emplean con frecuencia en las investigaciones sobre ciencias sociales. De manera bastante natural se extiende el concepto de capital a la migración y a la movilidad, en el sentido de la experiencia, de la capacidad para desplazarse y de las prácticas efectivas que llevan a los actores a construir sistemas complejos de movilidad. Pero la noción de capital de movilidad no puede resumirse

${ }^{1}$ Programa Metal (Metrópolis de América Latina en la Mundialización: Reconfiguraciones Territoriales, Movilidad Espacial, Acción Pública) que compara Santiago de Chile, São Paulo y Bogotá y ha sido financiado por la Agencia Nacional de Investigación (Francia). 
como la capacidad, en cada individuo, de ser móvil, de saber desplazarse y de viajar a diversos ámbitos locales o internacionales. Adoptaremos la hipótesis de que los procesos de capitalización de las prácticas de movilidad tienen amplitudes e intensidades variables dependiendo del grupo social, como complemento de otras formas de acumulación.

Puede admitirse que el aumento de la aptitud o de la capacidad para la movilidad urbana diversifica las oportunidades y amplía el universo de opciones, y en consecuencia favorece el acceso a los recursos presentes (educación, salud, empleo, cultura, etc.). Este encadenamiento sólo es posible si la movilidad potencial (conocimiento de la ciudad y también vínculos sociales) se transforma en movilidad efectiva sujeta a ciertas condiciones: aptitudes físicas, competencias (por ejemplo saber leer un plano del metro) y recursos (por ejemplo poseer un automóvil). De hecho, la movilidad efectiva puede estimular la movilidad potencial que a su vez la alimenta. En las ciudades marcadas por la segregación, que favorecen la especialización de los espacios urbanos, los desplazamientos son un modo de esquivar los entornos que favorecen la depreciación. Con el tiempo, este incremento en los desplazamientos genera de manera inevitable una organización de los modos de transporte, con una complejidad que se magnifica en las ciudades de gran tamaño. Para los habitantes esto supone una capacidad organizativa que se adapta para combinar la migración y la movilidad elemental (residencial y cotidiana) con nuevas formas transversales (multirresidenciales y pendulares). Son reales los riesgos de exclusión de los grupos socialmente desfavorecidos frente a normas de movilidad cada vez más exigentes (Orfeuil, 2004). En el transcurso de los años 2000 la aptitud para la movilidad se convierte en un reto social mayor para todos (Le Breton, 2005): para tener acceso a recursos escasos, distantes o que contribuyen a la promoción social; para mantener su posición social conjugando lugares de trabajo, lugares de residencia y lugares para diversas actividades; para evitar la exclusión social en la medida en que ser móvil exige competencias siempre más elevadas, e incluso cuando se trata de efectuar simples actividades básicas.

El concepto de capital de movilidad no ha sido objeto hasta ahora de una elaboración teórica consensual. Bourdieu insiste en sus reflexiones sobre el capital en las interrelaciones entre el espacio social y el espacio geográfico:

Las oportunidades que un grupo puede tener para apropiarse de cualquier clase de bienes raros (y que miden las capacidades matemáticas de acceso) 
Delaunay, Fournier y Contreras, ¿ES POSIBLE MEDIR EL CAPITAL...?

dependen parcialmente de sus capacidades de apropiación específica, definidas por el capital económico, cultural y social que puede instrumentar para apropiarse materialmente y/o simbólicamente de los bienes considerados, es decir de su posición en el espacio social, y por otra parte de la relación entre su distribución en el espacio geográfico y la distribución de los bienes raros en ese espacio (relación que puede medirse en distancias medias hacia bienes o equipamiento, lo cual hace intervenir el acceso a medios de transporte, individuales o colectivos). Dicho de otro modo, la distancia social real de un grupo a los bienes debe integrar la distancia geográfica, la cual depende a su vez de la distribución del grupo en el espacio [Bourdieu, 1979: 136].

Desde la época en que se realizaron esos trabajos las ciudades han cambiado de escala geográfica, las distancias de desplazamiento han aumentado, y en lo sucesivo los citadinos deben resolver de manera cotidiana ecuaciones espacio-temporales que ajustan sus itinerarios en función de una diversidad de restricciones y vicisitudes. Si bien las relaciones necesarias para la formación del capital social no pueden reducirse a las relaciones objetivas de cercanía en el espacio físico, la localización residencial y las capacidades para desplazarse cobran en nuestros días una importancia cada vez mayor en los procesos de inserción social. Las estrategias de movilidad se han vuelto indispensables para la inserción urbana. Vincent Kaufmann, entre otros autores, propone el concepto de "motilidad", definido como la manera en la cual un individuo o un grupo vuelve suyo el campo de lo posible en materia de movilidad y se sirve de él para desarrollar proyectos (Kaufmann y Jemelin, 2010).

Desde el punto de vista de la demografía, al considerar la acumulación de las capacidades se reintroduce la temporalidad, que es fundamental para la movilidad residencial que cambia en cada etapa del ciclo de vida. Esto ocurre en la medida en que un capital de movilidad se desarrolla (o se reduce) en medio de los ritmos cambiantes de los desplazamientos que exigen los calendarios profesionales, familiares y vitales. El sustrato del capital de movilidad es una combinación individual de movilidad antigua con capacidades y "potenciales" fundamentados en recursos económicos, con el saber-hacer, y con la localización; la movilidad se adquiere (no se nace "móvil") en medio de estímulos cambiantes y sobre todo por interacción con el entorno. El capital de movilidad abarca una dimensión colectiva a escala doméstica o de vecindario. De manera colateral, pero decisiva, tomar en cuenta el ciclo de vida conlleva a establecer asociaciones con el con- 
texto estructural del envejecimiento de la población, consecuencia de la transición de los regímenes demográficos, que en el contexto de Santiago impacta la movilidad (Delaunay, 2010).

El concepto sería especialmente apto para estimar las desigualdades frente a la movilidad, sencillamente porque una simple medida de frecuencia o de duración resulta insuficiente si no se sabe lo que es preferible; una misma práctica podría abarcar estrategias opuestas (Korsu, 2010). Por otra parte, la idea de una capacidad para desplazarse refleja más cualidades para abordar la complejidad de la demanda, que es también el resultado de una acumulación de experiencia, de localización en el espacio, de capacidad para asociar diferentes formas de movilidad o intercambio. El ejercicio es más pragmático que académico: es notoria la dificultad de discernir las desigualdades basándose únicamente en la intensidad, la distancia o la duración de los desplazamientos, o incluso en comportamientos que, a pesar de sus similitudes, no reflejan necesariamente una igualdad en los márgenes de maniobra a disposición de los individuos. Múltiples trabajos han mostrado que los individuos eran desiguales frente al dominio de la movilidad en las ciudades de América Latina (Fuentes y Sierralta, 2005; De Mattos e Hidalgo, 2007), y que estas desigualdades eran en gran parte el reflejo de la jerarquía social (Montezuma, 2003; Figueroa, 2005). Entre las clases medias y altas, que tienden a residir en las zonas o barrios más codiciados, a menudo cerca de los polos de empleos formales, de escuelas y hospitales reconocidos, se observa frecuentemente un aumento a largo plazo en la movilidad (cuantificada en número de desplazamientos) ligado a la mejora en la disponibilidad de automóviles por el hogar. Por el contrario, entre las clases populares, a menudo relegadas a la periferia del espacio urbano, se observa la limitación o la atrofia en el crecimiento de la movilidad y condiciones de desplazamiento más difíciles, especialmente en transportes colectivos cuyo costo aumenta a largo plazo y su peso es igual o mayor en el presupuesto de las parejas modestas que un vehículo particular para una familia adinerada.

La configuración general de Santiago ha evolucionado de manera notable en las últimas tres décadas. El sucesor del modelo de crecimiento periférico extensivo de baja densidad, que predominó hasta los años ochenta y que se tradujo en un despoblamiento de los sectores centrales, fue un esquema de desarrollo más complejo en el que muchas fuerzas intervinieron de manera simultánea. Mientras la implicación periférica sigue su curso, conllevando ubicaciones residenciales cada 
vez más alejadas y con un costo para la movilidad cotidiana cada vez más considerable (Rodríguez y Figueroa, 2008), las zonas centrales quedan sujetas a un proceso de redensificación que les permite atraer nuevos residentes (Contreras, 2006). De este modo la cuestión del cambio de modelo metropolitano remite a la evolución de las desigualdades socioespaciales, plantea la cuestión de la cohesión socioterritorial e invita al análisis de la emergencia de una "ciudad de velocidades múltiples", como ya se ha señalado en un marco europeo (Donzelot y Mongin, 2004). Por otra parte, varios autores abordan las cuestiones de exclusión social y espacial mediante la cuestión de las colonias privadas y cerradas (Cáceres y Sabatini, 2004; Borsdorf e Hidalgo, 2008) o al analizar los conjuntos habitacionales periféricos que definen lo que podría ser una "precariópolis" (Hidalgo, 2007), o incluso al concentrarse en explicar la formación de verdaderos guetos (Sabatini y Brain, 2008). Para L. Winchester las políticas de vivienda de interés social no se han integrado suficientemente con las políticas de acceso al mercado de trabajo (Winchester, 2008). Por esto la población que habita en colonias alejadas no tiene acceso a un empleo estable ni a ingresos regulares. Así, las cuestiones de la movilidad y de la desigualdad social interfieren directamente con las políticas públicas y la reconfiguración territorial.

En este contexto han emergido la coacción hacia la movilidad y la necesidad de construir nuevas infraestructuras de transporte para las clases altas, y también la necesidad de renovar con profundidad los sistemas de transporte público para las clases medias y desfavorecidas. Frente a estas cuestiones Santiago se nos presenta como una capital emblemática con un crecimiento económico vigoroso de más de tres décadas que ha dividido la pobreza entre tres, ha multiplicado el ingreso promedio por cinco, y que ofrece oportunidades inéditas de ascenso social (Delaunay, 2010). La instrumentación del Transantiago a partir de 2005 es un caso relativamente único de transformación radical del sistema de transporte para una aglomeración de tal magnitud -cerca de seis millones de habitantes para el Gran Santiago de 39 comunas-. Por otra parte, una política de vivienda de interés social que se ha sostenido desde hace treinta años ha facilitado el acceso de los estratos populares a la propiedad. Pero la cuestión de "Los con techo”, retomando el título de la obra de A. Rodríguez y A. Sugranyes, muestra las nuevas dificultades y desafíos a los que se enfrentan los habitantes, desde luego propietarios, pero que viven en colonias periféricas (Rodríguez y Sugranyes, 2004). Deben hacer frente a desplaza- 
mientos cotidianos costosos y discriminatorios o se ven forzados a adoptar una cierta inmovilidad y a replegarse hacia el ámbito local.

\section{El método de análisis y los componentes del capital de movilidad}

Para llevar a cabo la demostración se definirán tres objetos de análisis con el fin de deslindar lo que atañe a las capacidades y aptitudes para desplazarse (el capital de movilidad), a la práctica (la movilidad efectiva), y a un tercer grupo de características o de pertenencias que se tomarán como referencia para evaluar las discriminaciones estadísticas de las dos primeras. En el mejor de los supuestos cada objeto debería definirse por variables únicas, es decir, ausentes en los otros dos grupos. En efecto, la verificación de la brecha entre la aptitud y la práctica proscribe su medición por medio de descriptores vinculados estadísticamente. En el mundo real, sin embargo, esta exigencia metodológica se ve abatida por las colinealidades o endogeneidades que se ocultan en medio de ciertas características individuales: el nivel de escolaridad modifica a la vez el capital y la práctica, y éstos a su vez varían uno y otro con la edad, que es por sí misma una variable de control. La construcción de los componentes se apoya también en una hipótesis parcialmente verdadera de la independencia de ciertas formas de movilidad. Es probable que la experiencia migratoria acumulada a lo largo de la vida, que se utiliza para definir el capital de movilidad, no sea totalmente independiente de las prácticas cotidianas, en la medida en que la accesibilidad a la urbe depende del lugar y la fecha de nacimiento, y por lo tanto del estatus de inmigrante provinciano o extranjero. En cuanto a ciertas prácticas finas de movilidad (culturales) que hayan sido introducidas para circunscribir habilidades citadinas específicas, se observa que aparecen, no obstante, en las prácticas efectivas. En el presente estudio se muestran algunos casos razonados de inclusión que fueron verificados por medio de precauciones metodológicas tanto en el momento de construir sus índices como en su fase de análisis. En la etapa de definición de los objetos lo anterior se ha solucionado basándose en un análisis factorial (componentes múltiples) para construir los índices de capital y de movilidad. Más allá del uso habitual que se hace del método, el análisis factorial se instrumenta aquí para reducir una información compleja y de naturaleza heterogénea a índices simples y no correlacionados, con lo cual se restituye la información a su estructura esencial. El desafío no radica tanto en interpretar los ejes factoriales como en traducir de la mejor 
manera las variables seleccionadas para describir los componentes del capital de movilidad o las prácticas complejas, con el máximo posible de independencia entre los índices. Lo cual puede conducir a simplificaciones de la realidad. El esquema 1 resume las decisiones que se tomaron para definir los tres objetos y las fases del tratamiento de los datos.

Los índices propuestos son inevitablemente un compromiso entre las recomendaciones teóricas precedentes y las características y medidas que ofrece de manera efectiva la encuesta Metal-ANR (2009). El cálculo de indicadores de síntesis por medio de un ACM (análisis de componentes múltiples) se señala con la etiqueta "Score ACM". Estos indicadores son una suma ponderada de las modalidades de las variables seleccionadas, que tienen como vector de ponderación el peso obtenido por el ACM para la dimensión $t$ y la variable $i$.

$$
R_{i t}=\sum \frac{Z_{i h} A_{h t}}{q \sqrt{\phi t}}
$$

donde $A_{h t}$ es la matriz de las coordenadas estandarizadas, $q$ el número de variables activas en el análisis y $\phi_{t}$ el valor propio del componente principal. ${ }^{2}$ Se ha optado por el ACM porque requiere menos hipótesis sobre la linealidad de las relaciones entre las variables, que si bien rara vez se consigue, obliga a discretizar las variables continuas, ${ }^{3}$ lo cual se ha hecho de manera sistemática recurriendo a cuantiles o particiones simples (presente/ausente) para los eventos raros. Recordemos que este método es una extensión del que se utiliza comúnmente para construir índices de pobreza o de equipamiento a partir del inventario de bienes que posee el hogar (radio, teléfono, automóvil, bicicleta, etc.) (Booysen et al., 2008). Nosotros lo hemos incluido en la construcción de las capacidades colectivas del hogar (componente núm. 3).

$\mathrm{Al}$ mismo tiempo, y ésta es la segunda ventaja del método, la construcción de los componentes del capital de movilidad y la medición de las prácticas efectivas aportan un entendimiento sobre la manera en que se forman y estructuran. Por esta razón se presentan (muy someramente, por falta de espacio) algunas gráficas de los planos factoriales para entender cómo se posicionan entre ellas las diferentes

${ }^{2}$ Este cálculo fue efectuado utilizando Stata versión 11 por medio del comando predict que se ingresó después del comando MCA.

${ }^{3}$ Que incluso estaban raramente distribuidas de acuerdo con una configuración gausiana. 


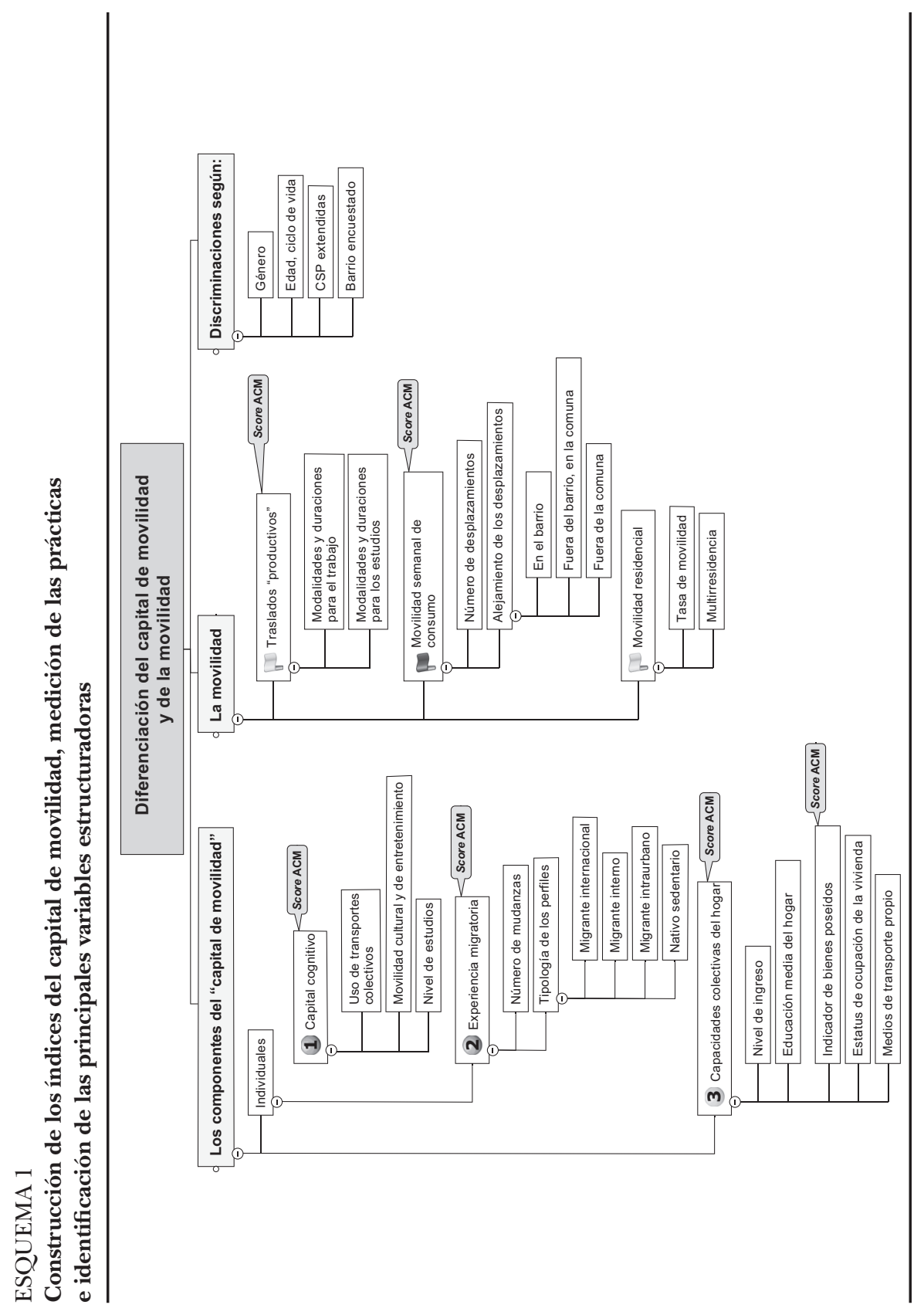


Delaunay, Fournier y Contreras, ¿ES POSIBLE MEDIR EL CAPITAL...?

modalidades de las variables y de esta manera dar sentido a los índices que se calculan. La manera en que cada variable contribuye a los componentes del capital de movilidad es en sí una información instructiva sobre las movilidades.

Una vez que el capital de movilidad y la movilidad se han descrito y cuantificado de manera independiente, se compara su variación de acuerdo con algunos grupos de edad, el género de los individuos y las categorías socioprofesionales reconocidos por la encuesta. Es obviamente posible enfocar desde otras perspectivas, pero resultaría de menor relevancia para nuestra problemática. Sin embargo se mencionarán, pero no se analizarán con detalle, las zonas encuestadas que revelan las discriminaciones que se asocian al lugar y al poblamiento. De las diez zonas estudiadas en la ciudad de Santiago, seleccionaremos tres para ilustrar las tensiones entre la capacidad y la práctica de la movilidad.

Como se muestra en las gráficas que se presentan a continuación, se han introducido dos niveles de información: el individuo y el hogar, que representa el contexto, y los medios compartidos entre los miembros. Los índices se calculan separadamente pero se han llevado al nivel elemental de los individuos, de manera que los que se refieren al hogar se ponderan por el número de individuos. ${ }^{4}$ Asimismo, no debemos olvidar que no se mide toda la movilidad de las personas. Las biografías se elaboraron a partir de un único adulto del hogar, quien también informa sobre la movilidad semanal de consumo (diversiones, compras, visitas, etc.), adoptando así la útil distinción de Bell y Ward (2000). En cuanto a la movilidad de trabajo o de estudio, que se asocia a la producción dentro de la clasificación citada, sólo se refiere a los individuos activos o los estudiantes.

Las estadísticas que se utilizaron provienen de una encuesta cuantitativa dedicada a la medición de las migraciones y la movilidad. Fue llevada a cabo entre junio y agosto de 2009 en 1004 hogares. Para lograr un enfoque monográfico más "cualitativo", la muestra se construyó tomando como base diez zonas del Área Metropolitana de Santiago ${ }^{5}$ conforme a la diversidad socioespacial de la ciudad (centro, pericentro, periferia y periferia alejada en formación), y también a sus principales

${ }^{4}$ Esta estructura jerárquica no tiene impacto en las comparaciones simples o de promedio, pero debe corregirse por medio de algoritmos multinivel en caso de modelos estadísticos.

5 1. Barrio Brasil-Yungay; 2. Lira-Almagro (Comuna de Santiago); 3. Santa IsabelProvidencia; 4. Recoleta-Independencia; 5. El Volcán; 6. Los Cóndores-Lira (Quilicura); 7. Huechuraba (Villa Esperanza y Villa Frei); 8. Chicureo; 9. Colina Tradicional; 10. Los Trapenses (Lo Barnechea). 
categorías sociales: clases altas, clases medias y grupos populares estigmatizados. Desde un punto de vista puramente estadístico, la muestra final no garantiza la representatividad de la zona metropolitana en su conjunto. Sin embargo, cada zona ilustra situaciones tipo de la trayectoria urbana. La ventaja de este procedimiento, que también tiene sus inconvenientes, radica en la asociación entre las estadísticas de cada zona $^{6}$ y la observación profundizada de ésta, de carácter monográfico, en la que además se analizan los testimonios de sus habitantes. Mediante el cuestionario se pretende abarcar toda la gama de prácticas de movilidad, especialmente a escala biográfica en el caso de las trayectorias residenciales y profesionales. En los tratamientos y los resultados que aquí se presentan sólo se incluye a los individuos mayores de cinco años, es decir, a 3250 personas. La movilidad de consumo, entendida como el conjunto de prácticas urbanas que no implican los traslados ligados al trabajo o al estudio, se documenta a partir de un efectivo de un millar de personas.

\section{Los componentes individuales del capital de movilidad}

El primer componente evalúa la capacidad organizativa o cognitiva del individuo que se desplaza en la zona metropolitana. El segundo muestra la capacidad migratoria acumulada, que está condicionada por la selectividad inevitable de la migración (tanto en el momento de partir como en el de instalarse), además de la capacidad para escoger su lugar de residencia en una ciudad y en el interior de ésta.

Por lo tanto, el análisis exploratorio del primer componente -el capital cognitivo de la movilidad-considera el nivel de estudios tomando como criterio los ciclos de estudio concluidos y, por otra parte, la capacidad de tomar transportes colectivos, estimada en su uso efectivo. ${ }^{7}$

${ }^{6}$ Los hogares fueron seleccionados al azar mediante un sistema de cuotas que respetó el tipo de edificio, la edad del jefe de la familia y el tamaño de ésta.

7 Muchos testigos interrogados dijeron que les parece complicado utilizar el Transantiago, un sistema de metrobús con sus propias paradas. La medición simple de los desplazamientos es el proxy de una capacidad que cambia sensiblemente entre una zona y otra las normas culturales. Un trayecto corto a pie o en bicicleta puede tener significados opuestos dependiendo de los lugares y de las clases sociales. En el barrio El Volcán esto corresponde a una necesidad, a la ausencia de otros modos de transporte o a falta de dinero. Para los habitantes de Los Trapenses, más liberados en su mayoría de las restricciones financieras o logísticas, estos modos reflejan una forma de vida agradable. Por el momento nos abstendremos de modular el análisis por barrio, pero no sería imposible hacerlo. 
Delaunay, Fournier y Contreras, ¿ES POSIBLE MEDIR EL CAPITAL...?

MAPA 1

Santiago de Chile y zonas abordadas por la Encuesta Metal

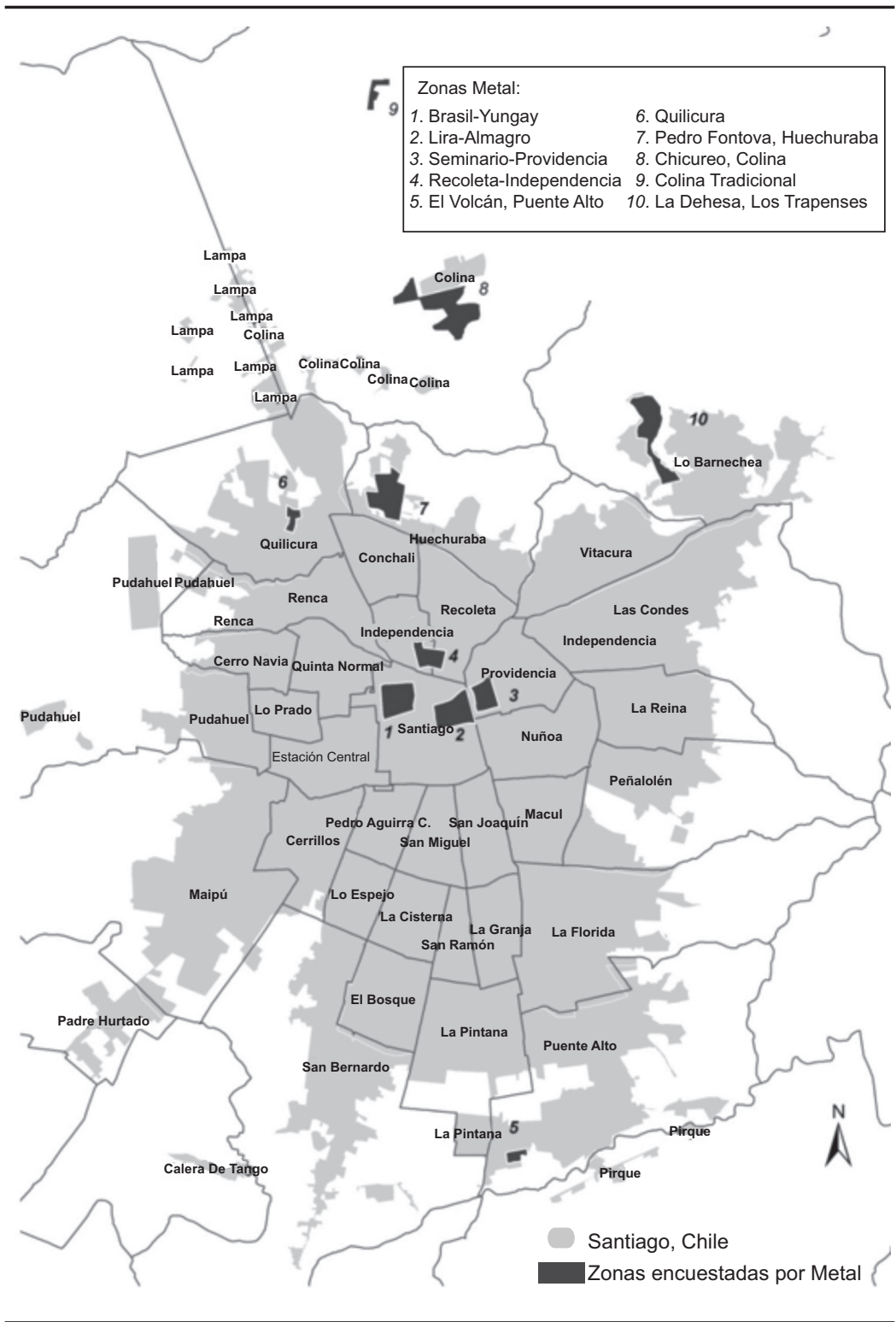

FUENTE: Elaboración propia con base en la Encuesta Metal, 2009. 
Nuestro interés por escuchar las entrevistas cualitativas fue el otro motivo por el cual prevaleció la idea de introducir una forma distinta de movilidad. El hecho de desplazarse en la zona metropolitana para ir al museo, al teatro, al cine, pero también al restaurante, no muestra solamente una forma privilegiada de consumo cultural, además traduce la facilidad para desplazarse en la ciudad hacia sitios que no todos conocen ni frecuentan. ${ }^{8}$ La variable es el proxy de una alta disposición a la movilidad urbana de consumo (véase la gráfica 1). Los scores del primer eje principal estiman el capital cognitivo que varía con la educación, en donde la formación universitaria marca la diferencia. Los desplazamientos culturales (cero, uno por semana, dos y más) son aún más distintivos. Su ausencia, en cambio, se sitúa en medio de todos los no universitarios. Los desplazamientos frecuentes que van más allá son más elitistas. El uso del transporte público es especialmente crítico en el eje 2, el cual nos recuerda que la no utilización caracteriza a las personas situadas en la parte baja de la escala social, y en menor medida, a aquellas que poseen una formación superior y que prefieren el uso del automóvil.

La experiencia migratoria se describe a partir de la trayectoria biográfica que se obtuvo de cada individuo, ${ }^{9}$ de lo cual se deducen dos informaciones: el número total de etapas residenciales ${ }^{10}$ y una serie de estatus migratorios simples, en función del lugar de nacimiento y de la experiencia residencial. Como se aprecia en la gráfica 2 , se distinguen los migrantes internacionales, los migrantes provincianos, los nativos de la zona metropolitana y aquellos que han efectuado un desplazamiento intraurbano en la misma zona. El eje 1 (55\% de la inercia) contrapone en el lado derecho de los valores positivos de las abscisas a los sedentarios y los citadinos nacidos en la zona metropolitana frente a los migrantes del extranjero y de las regiones, en negativo. El número de estancias confirma esta graduación. Para conservar un

${ }^{8}$ Otros indicadores eran y seguirán siendo posibles. Frecuentar o no los sitios más representativos de la ciudad ha sido tomado en cuenta, lo cual traduce el conocimiento que tienen los habitantes del espacio urbano, si lo frecuentan. Hay lugares que de hecho están fuera del alcance de algunos habitantes de la urbe.

${ }^{9}$ La tipología es rudimentaria para facilitar su comprensión y conservar solamente los principales perfiles de migrantes, pero también porque se han utilizado dos fuentes para construirla: una biografía elemental reconstituida para todos y que no puede ir más allá, y una biografía detallada pero que sólo se refería a una submuestra restringida y sesgada hacia los jefes de la familia.

${ }_{10}$ Se trata efectivamente de etapas residenciales, estancias truncas incluidas (observadas en el momento de la encuesta antes de una mudanza). Una única estancia corresponde por lo tanto a los sedentarios, que no se consideran móviles sino a partir de la segunda estancia. 


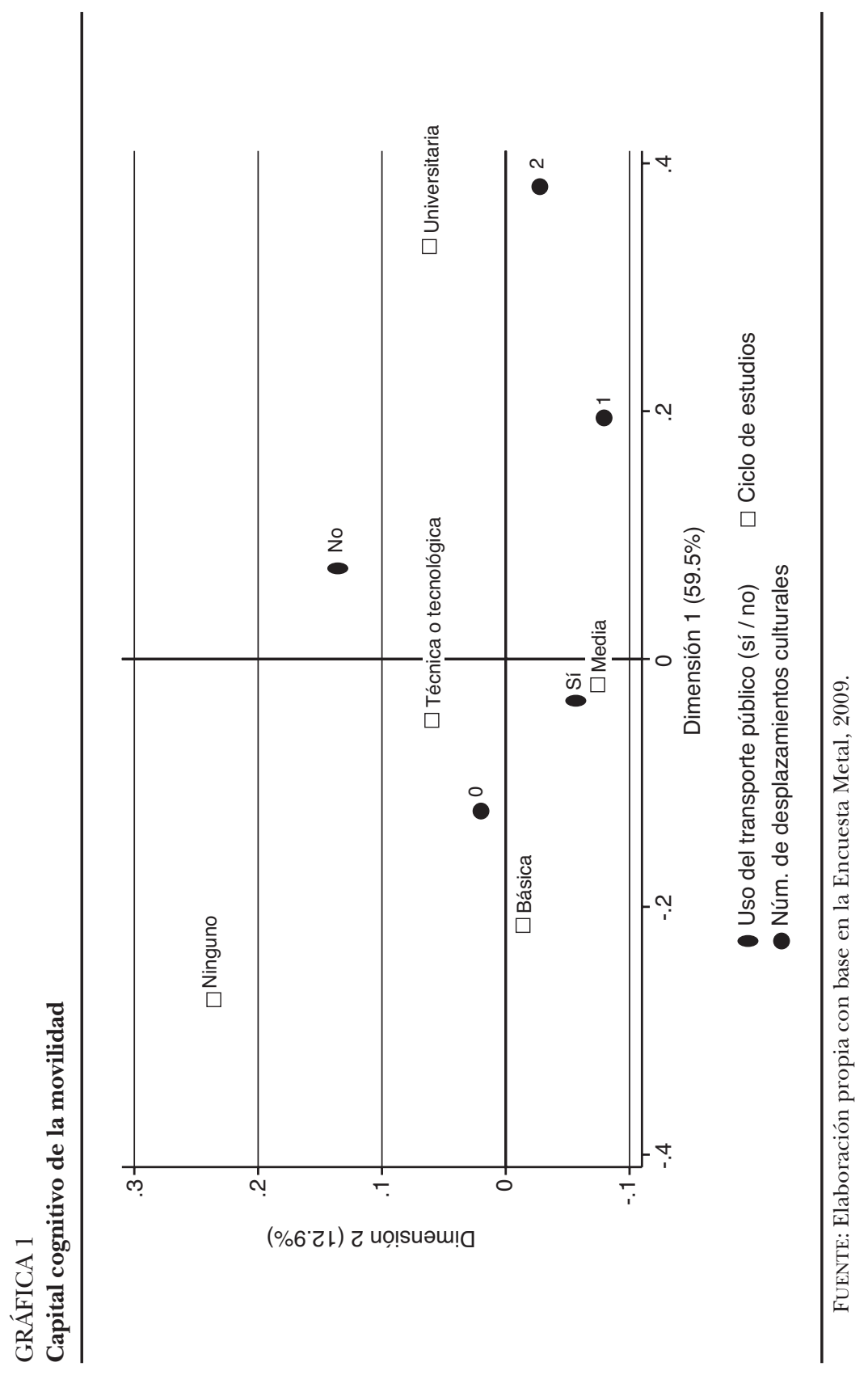




\section{GRÁFICA 2}

Experiencia de movilidad residencial

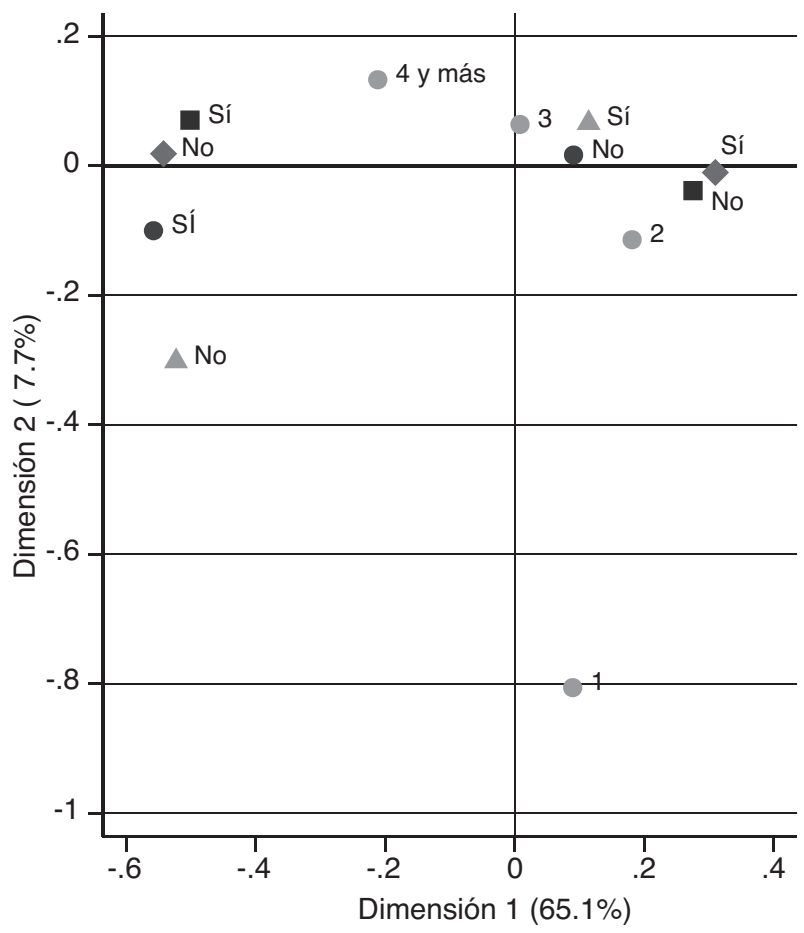

- Migrante internacional

- Migrante de las regiones

Nativo de la zona metropolitana

A Migrante intraurbano

- Núm. de etapas

FUENTE: Elaboración propia con base en la Encuesta Metal, 2009. 
índice que mida la experiencia migratoria se invierte el signo del índice para denotar una experiencia mayor en el caso de los valores positivos. El eje 2, como ordenada, no es menos importante y refleja otra realidad que es la movilidad residencial intraurbana. Esta dimensión también se ha seleccionado en el análisis para designar dicha práctica, en la que se distingue una tendencia que afecta más a los provincianos que a los extranjeros.

\section{El componente colectivo: equipamiento en el hogar}

En materia de movilidad residencial, pero también de orden cotidiano, los miembros de un hogar comparten una misma ubicación en la ciudad, ${ }^{11}$ las comodidades, y entre éstas la disponibilidad de medios de transporte, una parte del ingreso, el nivel de vida, etc. Una ama de casa, por ejemplo, puede no disponer de ingreso propio en un colectivo de clase alta; de hecho sobre esa variable sólo se ha interrogado en este nivel de la unidad doméstica. Se calculó un índice de equipamiento como proxy del nivel global de equipamiento a partir de los bienes que se encontraron en el domicilio: teléfono, internet, televisión, calefacción, etc. Sin embargo, para señalar claramente las capacidades físicas para desplazarse, una variable de control indica la presencia de un vehículo motorizado particular que es propiedad del hogar. Generalmente los autores consideran el estatus de ocupación de la vivienda como una restricción para la inmovilidad/movilidad y un componente del valor simbólico de la movilidad (Jouffe, 2010). Esto es especialmente cierto en el caso de Santiago, en donde se llevó a cabo durante varias décadas una política de vivienda propia de interés social en colonias periféricas, modestas e incluso pobres y desatendidas (Paquette, 2000). En la reconstrucción del capital compartido se distinguen la propiedad, el alquiler y, agrupados, el usufructo y el uso a título gratuito. El índice de equipamiento se discretiza en cuantiles, y esto es en realidad un indicador de subequipamiento para los valores elevados de la medición. Finalmente se agrega un valor discreto (por cuantiles) del número promedio de años de estudio de los miembros del hogar mayores de 18 años con el fin de contextualizar la educación individual inducida por el capital cognitivo. Se trata de fortalecer el peso del componente socioeconómico del hogar.

${ }^{11}$ Salvo en el caso de multirresidencia, la cual es tratada con la movilidad residencial. 
Como se aprecia en la gráfica 3, la primera dimensión está claramente señalada ( $80 \%$ de inercia) y se interpreta sin dificultad partiendo de los hogares más pobres, los menos educados y los menos equipados, hacia la adquisición progresiva de esas cualidades. El agrupamiento de las categorías con más carencias es especialmente estrecho en torno a los ingresos, al subequipamiento y a la educación. Un grupo se superpone precisamente a la zona de El Volcán (comuna de Puente Alto, en la periferia sur de la ciudad), que tomaremos como ejemplo. Es igualmente interesante la posición de la variable que identifica los hogares con un medio de transporte propio. No se ubica en los extremos: no son solamente los muy pobres los que carecen ni los muy ricos los que poseen dicho medio.

El estatus de ocupación es menos discriminatorio. Si bien el alquiler, el usufructo y el uso de forma gratuita están al alcance de las familias con menos ingresos, la propiedad se mantiene en una posición central debido a la vivienda de interés social y al financiamiento subsidiado para el acceso a la propiedad. Se justifica la conservación del score del eje 1 para medir el nivel económico del hogar y sus capacidades para desplazarse. La segunda dimensión, anecdótica, ha sido excluida (véase la gráfica 3).

La gráfica 4 muestra la disposición de la geografía social de las zonas encuestadas que se seleccionaron para representar la ciudad. Éstas se ubican en el plano de los dos ejes de la composición del capital doméstico. Las zonas no contribuyen a definir los ejes del plano factorial. De izquierda a derecha y siguiendo el ascenso del nivel de vida y de educación, se encuentra El Volcán, el barrio pobre más emblemática en el sur de la zona metropolitana; luego zonas centrales como Barrio Brasil, Yungay (comuna de Santiago), y después fraccionamientos ricos de reciente creación en las periferias septentrionales y nororientales, tales como Los Trapenses (comuna de Lo Barnechea).

\section{La movilidad}

Finalmente resultó más complicado obtener una medida homogénea de la movilidad a partir de los datos que proporcionó la encuesta Metal, a pesar de, o incluso debido a, la amplia gama de las prácticas obtenidas, ya que no todas se miden para todos los encuestados ( $c f$. supra). El desglose que se presenta a continuación solo abarca tres conjuntos que pretenden conservar la mayor cantidad de individuos. 


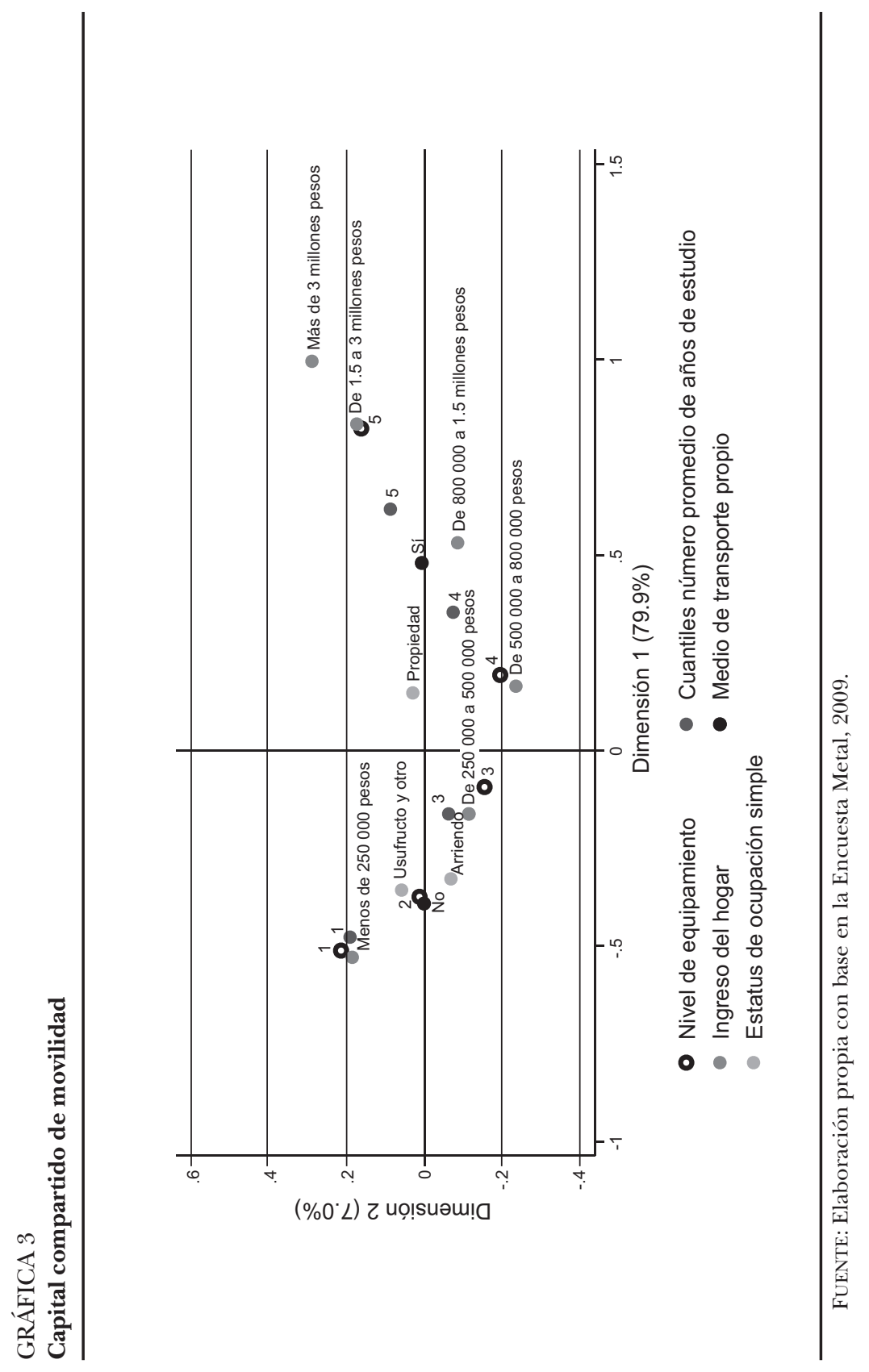




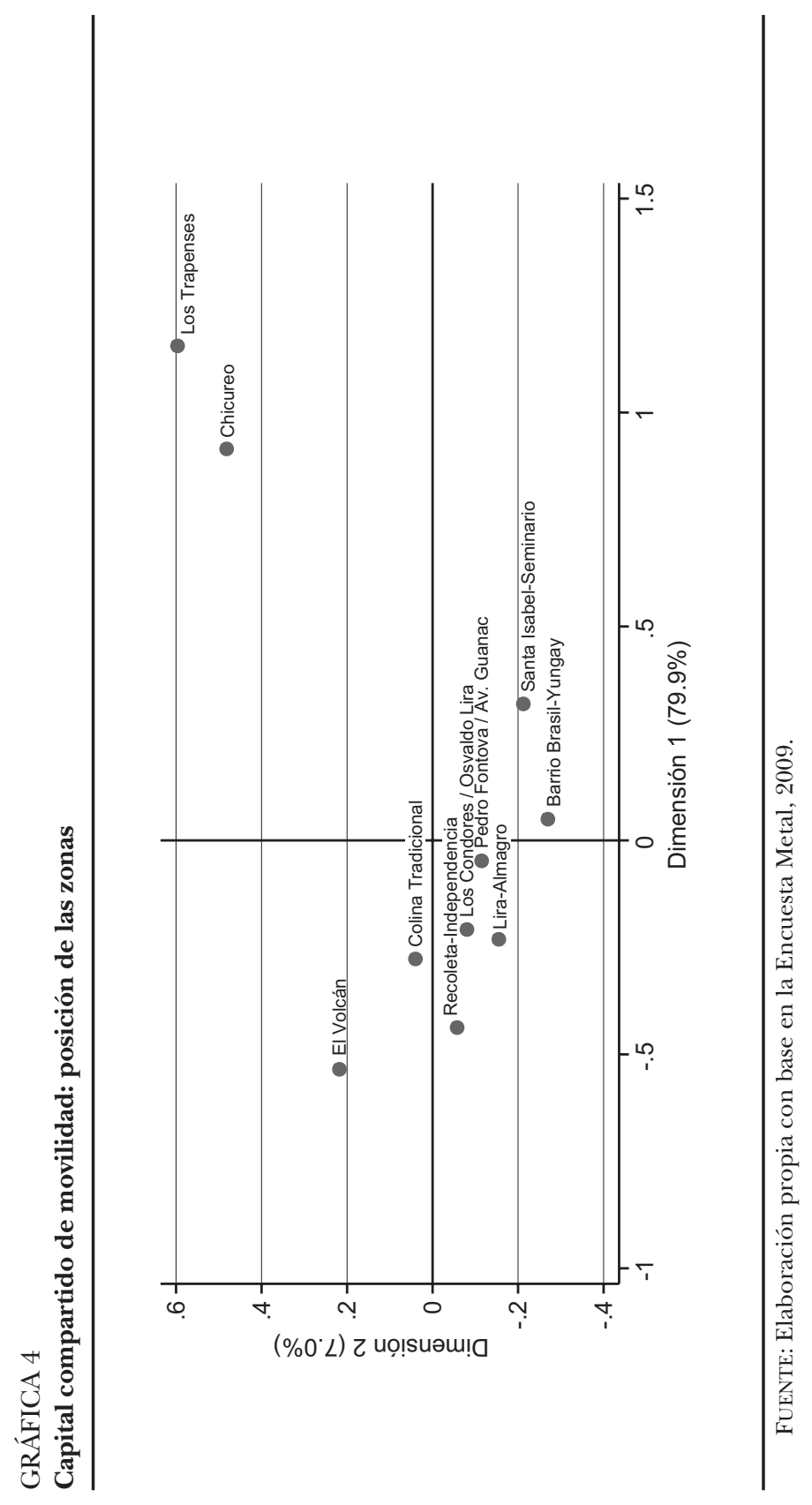


Delaunay, Fournier y Contreras, ¿ES POSIBLE MEDIR EL CAPITAL...?

\section{La movilidad productiva: trabajo y estudio}

Los traslados entre el domicilio y el lugar de trabajo o de estudio se registran para todas las personas que los realizan, es decir para los activos y los estudiantes que se desplazan, lo cual deja de lado a los trabajadores cuyas actividades se practican en su domicilio. Se han seleccionado dos informaciones: los modos significativos de transporte (automóvil, autobus...) y la duración declarada del trayecto, discretizada por cuantiles. Los modos de transporte se refieren a las actividades ocupacionales primarias y secundarias, combinadas, y con prevalencia de la primera sobre la segunda cuando las dos están presentes. El resultado es interesante, pues más que una duración promedio por moda se revela la dificultad de los trayectos cotidianos que implica la actividad. Para apreciar la discriminación, el índice resultante se presenta como una buena alternativa a las medidas directas, como la duración o la frecuencia.

La gráfica 5 se refiere a la movilidad entre el domicilio y el lugar de trabajo. Dada la importancia del primer eje (84\% de la inercia), está más que justificado limitarse con éste. La graduación de los tiempos de transporte es regular; los más largos se asocian a los transportes colectivos terrestres, entre los cuales destaca el Transantiago, que simboliza la renovación de los transportes públicos y para el cual podemos observar una posición extrema en la escala de conveniencia. En el orden de aparición siguen los transportes privados (empresa), un poco más convenientes que el metro. El automóvil ocupa una situación intermedia que facilita el recorrido de mayores distancias (la moto es marginal en Santiago). En el extremo derecho de los trayectos sin dificultad (transporte personalizado y de corta duración) aparecen los taxis y la marcha a pie. Para que el índice muestre un crecimiento paulatino de la dificultad, se ha invertido el signo del score.

Como se aprecia en la gráfica 6 , la movilidad estudiantil tiene una configuración similar, con matices que caracterizan a los agrupamientos modales como el taxi y el automóvil particular. La posición extrema, que penaliza los taxis colectivos y los autobuses, se confirma especialmente cuando incluye el transporte escolar destinado a este uso específico, en lo cual se asimila al transporte privado que está a disposición de los centros de trabajo. La marcha a pie se confirma como el desplazamiento más rápido y menos restrictivo. 


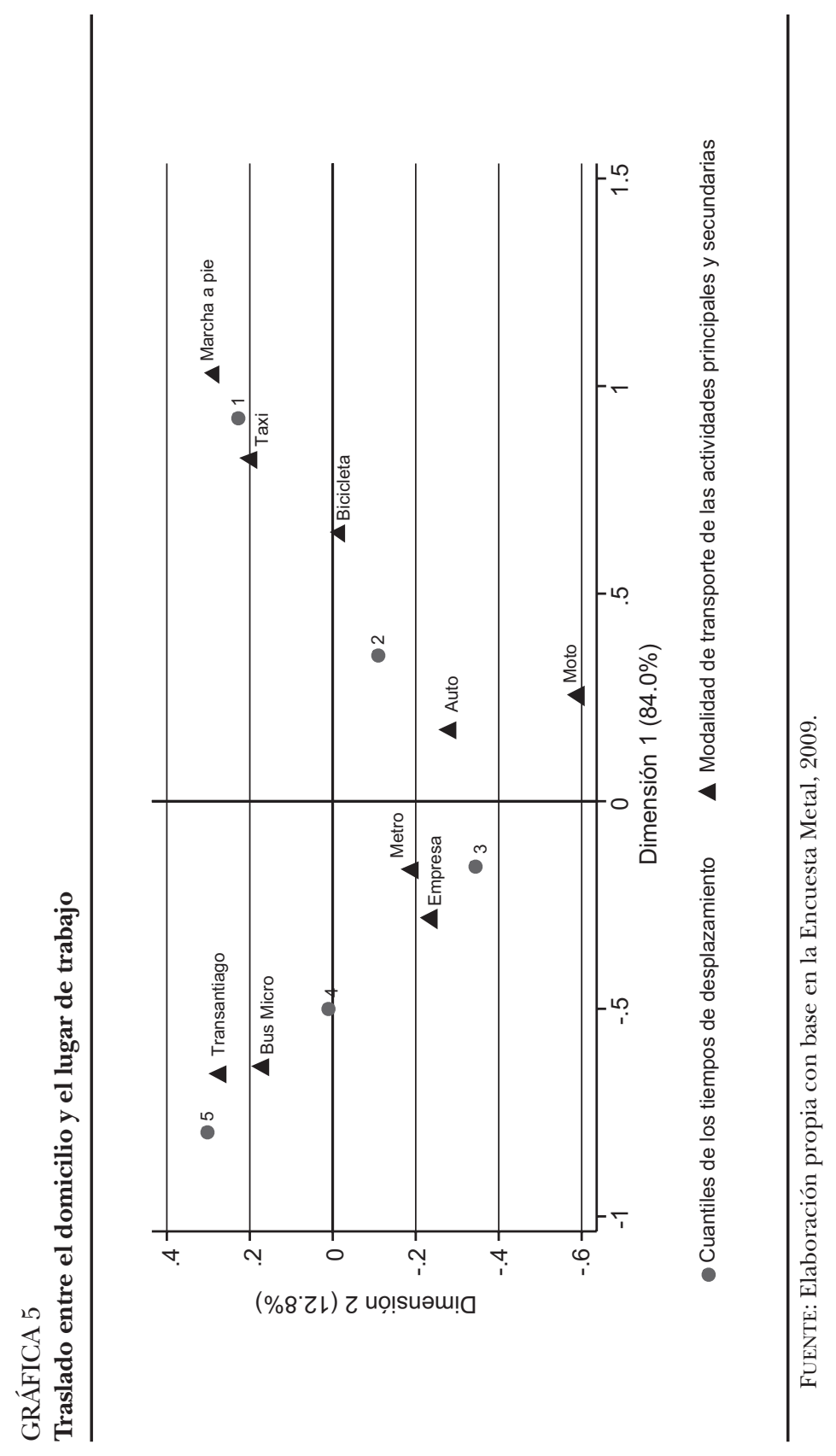




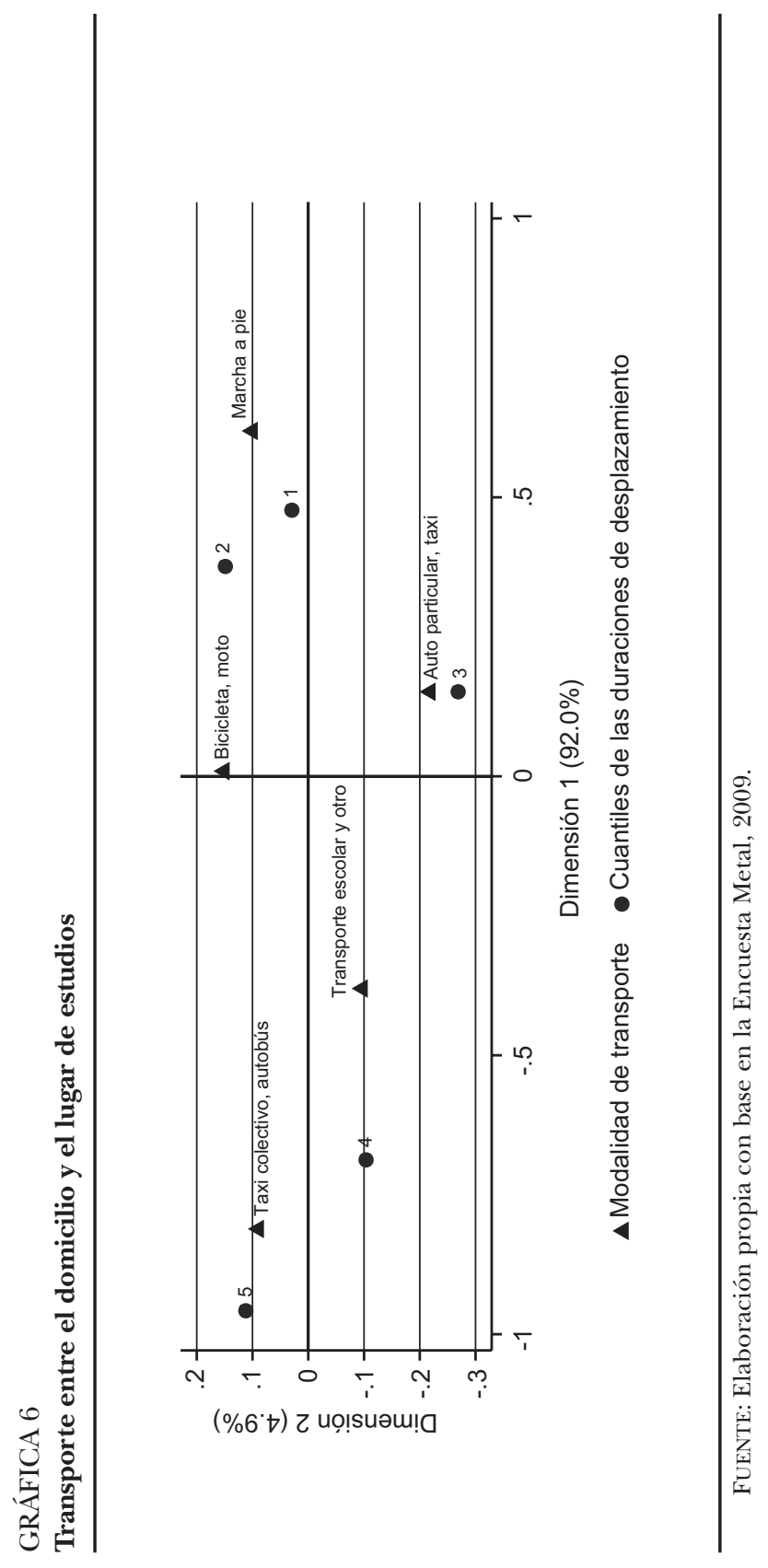




\section{La movilidad de consumo}

El protocolo de la investigación sólo plantea las preguntas relativas a las prácticas urbanas a los individuos que fueron escogidos por sorteo para responder al cuestionario biográfico, de ahí que la muestra no carezca de sesgo. ${ }^{12}$ La intensidad de la movilidad se expresa en la frecuencia de los desplazamientos dependiendo de los motivos, y la completa la distancia en función del paso entre límites administrativos: barrio, comuna. ${ }^{13}$ Asimismo, los modos de transporte se documentan en función de una serie de motivos. En síntesis, la información es compleja y por ello difícil de sintetizar. El análisis por múltiples componentes no revela una estructura muy contrastante, que puede examinarse con mayor propiedad en los pormenores de las combinaciones con pocas modalidades. Los habitantes de la periferia septentrional se desplazan mucho, pero sobre todo en automóvil, y con muy poca frecuencia en su entorno inmediato. En el extremo opuesto, quienes residen en El Volcán, barrio pobre de la periferia, se desplazan de manera casi exclusiva a pie dentro de su zona. Destaca el papel de la ubicación en la urbe sobre estas prácticas por la cercanía de los barrios vecinos. En el centro, Brasil y Santa Isabel comparten una posición media en cuanto a la intensidad de la movilidad, con un abanico extendido de modos. El análisis fino de estas combinaciones bastante predecibles es poco relevante para nuestro estudio, sobre todo porque los ejes principales no revelan un fenómeno que pueda interpretarse directamente en términos de práctica de movilidad para el entretenimiento o el consumo. De manera más precisa, el número de desplazamientos prevalece sobre el eje 1 pero con una inercia reducida. Al final parece preferible atenerse al valor bruto de la frecuencia de los desplazamientos, discretizado de acuerdo con los deciles, lo cual refleja un grado de intensidad creciente de la movilidad de consumo.

12 Se selecciona al azar un individuo por hogar, de manera que los hogares con pocos efectivos están sobrerrepresentados. Por otra parte, la gran desconfianza de las clases medias ocasionó la negativa a participar en la encuesta en complejos residenciales cerrados. La muestra de las biografías sobrerrepresenta a las personas: amas o dueñas de casa, de edad avanzada, menos educadas. Por todo lo anterior estas restricciones sólo se refieren a la movilidad de consumo que, tal como la medimos, incluye a todos los adultos.

13 La delimitación seleccionada de la zona metropolitana cuenta 36 para seis millones de habitantes hacia 2005. 
Delaunay, Fournier y Contreras, ¿ES POSIBLE MEDIR EL CAPITAL...?

\section{La movilidad residencial}

El primer índice que se experimenta es la multirresidencia, con el cual se designa a las personas que se han ausentado de su domicilio principal por un periodo superior a un mes, pero este evento es demasiado raro (4 de 100 individuos) y específico para representar al fenómeno. El índice más sintético es el número promedio anual de mudanzas, o bien una tasa de movilidad/migración que afecta a todo el conjunto de la trayectoria pero que puede variar con la edad. Para abarcar a la población en forma más amplia se ha utilizado la biografía simplificada, que siendo algo menos precisa, complementa a la biografía completa.

\section{La diferenciación del capital de movilidad y las prácticas}

Más allá de la comprensión de la movilidad, la finalidad de estos índices es aclarar si la capacidad para desplazarse cambia la práctica, su intensidad o su costo; si exacerba la fuerza discriminatoria de las características demográficas o los estatus socioprofesionales. El género es la primera de las discriminaciones posibles, el cual toma en cuenta los papeles que desempeñan hombres y mujeres, y entre ellos la presencia obligada en el hogar para asumir las cargas de la educación. La edad acompaña los cambios de la movilidad, que son prácticamente universales a lo largo de las diferentes etapas del ciclo de vida -con la adquisición de la autonomía por medio del trabajo, de la unión, de la pérdida de la cohabitación con los padres-y entre generaciones. También impulsa la variación de la movilidad cotidiana, especialmente en el caso de Santiago (Delaunay, 2007 y 2010), ya sea por un acercamiento parcial hacia el lugar de trabajo o por la elección de actividades menos distantes. Por otra parte, estas variaciones anticipan un retroceso relativo de la movilidad en función del envejecimiento de las poblaciones urbanas, una vez transcurrido el periodo de transición demográfica. Finalmente, de las categorías socioprofesionales dependen las condiciones económicas para desplazarse, tanto en el plano cotidiano como en el residencial. Sobre todo implican empleos distribuidos de forma desigual en el espacio. Nuestra propuesta es extender las categorías socioprofesionales (CSP) clásicas a formas diferenciadas de inactividad (estudiantes, jubilados, amas de casa, etc.) con el fin de incluir a toda la población, pero también para poder observar catego- 
rías que tal vez reflejen algunas carencias de capital de movilidad, o que experimenten una depreciación de sus prácticas urbanas.

Sintetizaremos las medidas por comparar: cuatro se refieren a los componentes del capital de movilidad, y tres a diferentes prácticas de movilidad. Por el hecho de haber obtenido su modo de cálculo utilizando el ACM, es oportuno hacer un recuento del sentido de su graduación (véase el cuadro 1).

\section{El género, poco discriminatorio}

En cada uno de los registros del capital de movilidad estimado se observa una brecha menor entre ambos sexos: la experiencia migratoria "distante" es un poco más intensa entre las mujeres, con excepción de la que se construye en el espacio intraurbano; el capital cognitivo es mayor entre los hombres debido en parte, aunque no únicamente, al bajo nivel educativo de las mujeres entre las poblaciones de mayor edad (movilidad de ocio); en cambio el capital del hogar es mayor entre las mujeres. Grosso modo el equilibrio se alcanza por suma cero. Por el lado de la movilidad productiva, las mujeres reflejan un déficit considerable: los hombres están sobrerrepresentados en los cuantiles elevados y también son mayoría los que la practican. Una prioridad parece establecerse en las negociaciones en el interior del hogar en conformidad con el capital cognitivo, a pesar del contexto colectivo que es más favorable hacia las mujeres. No aparece ninguna diferencia significativa entre los indicadores de movilidad de consumo, pero la muestra no alcanza para despejar la incertidumbre estadística. Las mujeres practican mucho más la multirresidencia, pero de nuevo los intervalos de confianza inducen a la duda; la misma observación es válida para las tasas de movilidad residencial. En resumen, no se dispone de algún elemento estadístico que cuente con la solidez necesaria para establecer una discriminación entre los sexos.

\section{La etapa de la vida según la edad del momento}

Para evitar el innecesario esfuerzo de comparar efectivos escasos y poco significativos, y porque la movilidad de los jóvenes depende de los padres, el seguimiento de acuerdo con la edad sólo abarcó de los 20 años a los 74. Las variaciones de los cuatro componentes están bien 


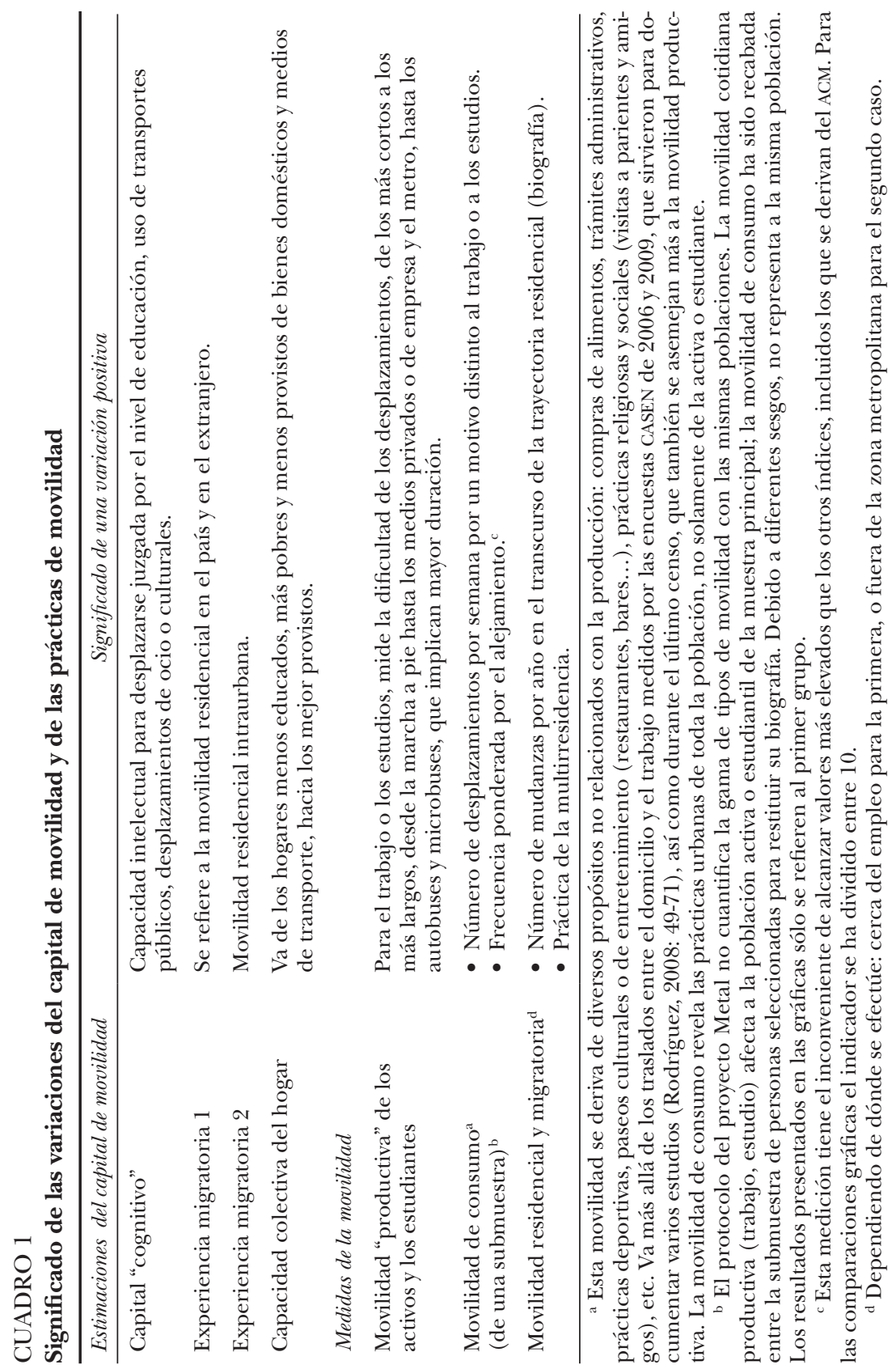


diferenciadas: en forma de campana para el capital cognitivo, un poco menor para los jóvenes menores de 30 años, máxima en la plenitud de la vida activa, y luego en declive, especialmente para las personas de más de 60 años y menos de 75. En cambio -y esto no sorprende dada la definición del índice- la experiencia migratoria aumenta. Ésta es particularmente alta para los individuos de mayor edad, que son en su mayoría migrantes en la ciudad. El incremento del capital colectivo requiere tanto tiempo como el de su acumulación y luego vuelve a caer entre las personas mayores, menos equipadas.

Para las prácticas reales, las cifras indican que la movilidad residencial es la más suelta de las capacidades estimadas. La multirresidencia se practica de manera más intensa entre los adultos jóvenes y las personas mayores, quienes recurren con mayor frecuencia al hospedaje de manera provisional. La tasa de migración media se eleva para los jóvenes, ya que sólo se toma en cuenta el periodo más intenso de movilidad residencial. La dificultad de la movilidad productiva tiende a disminuir considerablemente con la edad, para reducirse de manera radical hacia el final del ciclo vital, cuando la actividad caracteriza a aquellos que aparentemente son más libres de elegir. Los más jóvenes, quienes están cursando sus estudios, pagan el precio más elevado en tiempo de desplazamiento, entre otras razones porque utilizan más los transportes colectivos, mientras que los de 30 a 44 años son los más beneficiados con la adquisición de medios propios para el acercamiento hacia el lugar de trabajo. La mejora es más amplia que la de su capital cognitivo o doméstico de movilidad, ya que el cognitivo retrocede a los 45-59 años (¿un efecto generacional?) y luego claramente después de los 60 años, pero para una población sin actividad. Las variaciones del índice de movilidad de consumo son más moderadas, sobre todo considerando intervalos de confianza bastante amplios. La movilidad cotidiana para el trabajo marca la tendencia y gana confort durante el ciclo de vida conforme al aumento de las capacidades, y aparentemente más allá, incluso si las amplitudes de variación no tienen el mismo sentido entre un índice y otro (véase la gráfica 7).

\section{Las categorías socioprofesionales}

Las diversas categorías socioeconómicas del capital de movilidad contrastan claramente en la dirección prevista. Una experiencia migratoria fuerte corresponde obviamente a las personas mayores (jubilados), 


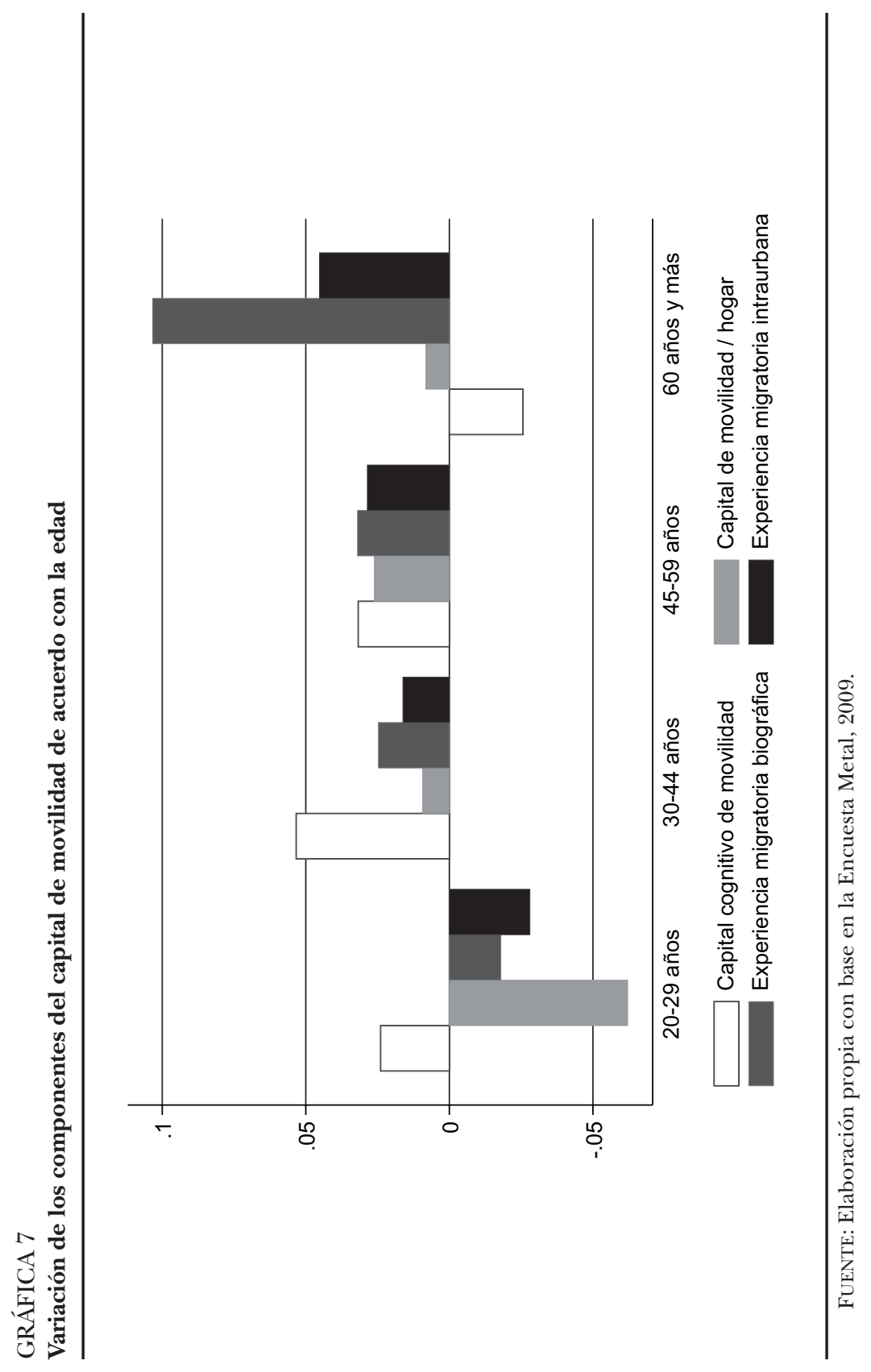


pero también a los trabajadores domésticos no calificados, y en menor grado a los ejecutivos o empleados de mandos medios, categorías derivadas en gran parte de la inmigración de origen provinciano. La dimensión urbana de la movilidad residencial está menos diferenciada, pero se hace patente la capacidad de las clases altas y medias, al igual que la de los domésticos "desplazados", entre un empleador y otro. El capital cognitivo positivo distingue las clases medias de las altas de manera muy clara, y el equipamiento del hogar desfavorece muy especialmente a los obreros y trabajadores poco calificados, que siguen sin ambigüedades el nivel socioeconómico en todos los pormenores de cada categoría. Los domésticos adolecen de un déficit más de orden personal que colectivo, que se ve atenuado por el alojamiento que les proporcionan los empleadores (véase la gráfica 8).

Comparada con las capacidades de los activos y de los estudiantes, la movilidad productiva parece obedecer a una lógica propia, pero una vez descartadas las situaciones particulares revela una verdadera discriminación. Los desempleados y los trabajadores no calificados combinan capacidades menores y una movilidad menos apremiante con diferencias respecto a la experiencia migratoria que denota sus orígenes geográficos. Por lo que parece, sufren menos las exigencias que impone el lugar del trabajo, ya que se alojan en las obras o en el domicilio del empleador, o se desplazan de manera económica, por ejemplo a pie. Las élites, mandos superiores y gerentes presentan a la vez la movilidad más ágil y el capital más elevado, lo que los distingue de los mandos medios y sobre todo de los obreros y estudiantes, que deben dirigirse a su centro de actividades pagando precios de transporte costosos y menos eficaces. Por otra parte, éstos disponen del nivel más bajo de capital, de ahí que la desigualdad deba más a esta brecha entre la capacidad y la práctica que a los dos componentes de manera aislada. Una y otra pasan al valor negativo respecto al promedio. ${ }^{14}$ Los mandos medios se sitúan en una posición intermedia (véase la gráfica 8$)$.

La movilidad de consumo -estimada, recordémoslo, en términos de frecuencia y distancia, y dentro de una población más reducida- ${ }^{15}$ presenta un perfil más regular, graduado no obstante en función del nivel socioeconómico. En este orden, los obreros, los desempleados y los trabajadores no calificados registran el menor número de despla-

14 Recordemos que los scores han sido centrados y reducidos.

${ }^{15}$ Dependiendo de lo que eligen las personas que informan sobre la movilidad cotidiana, que son las menos numerosas. 


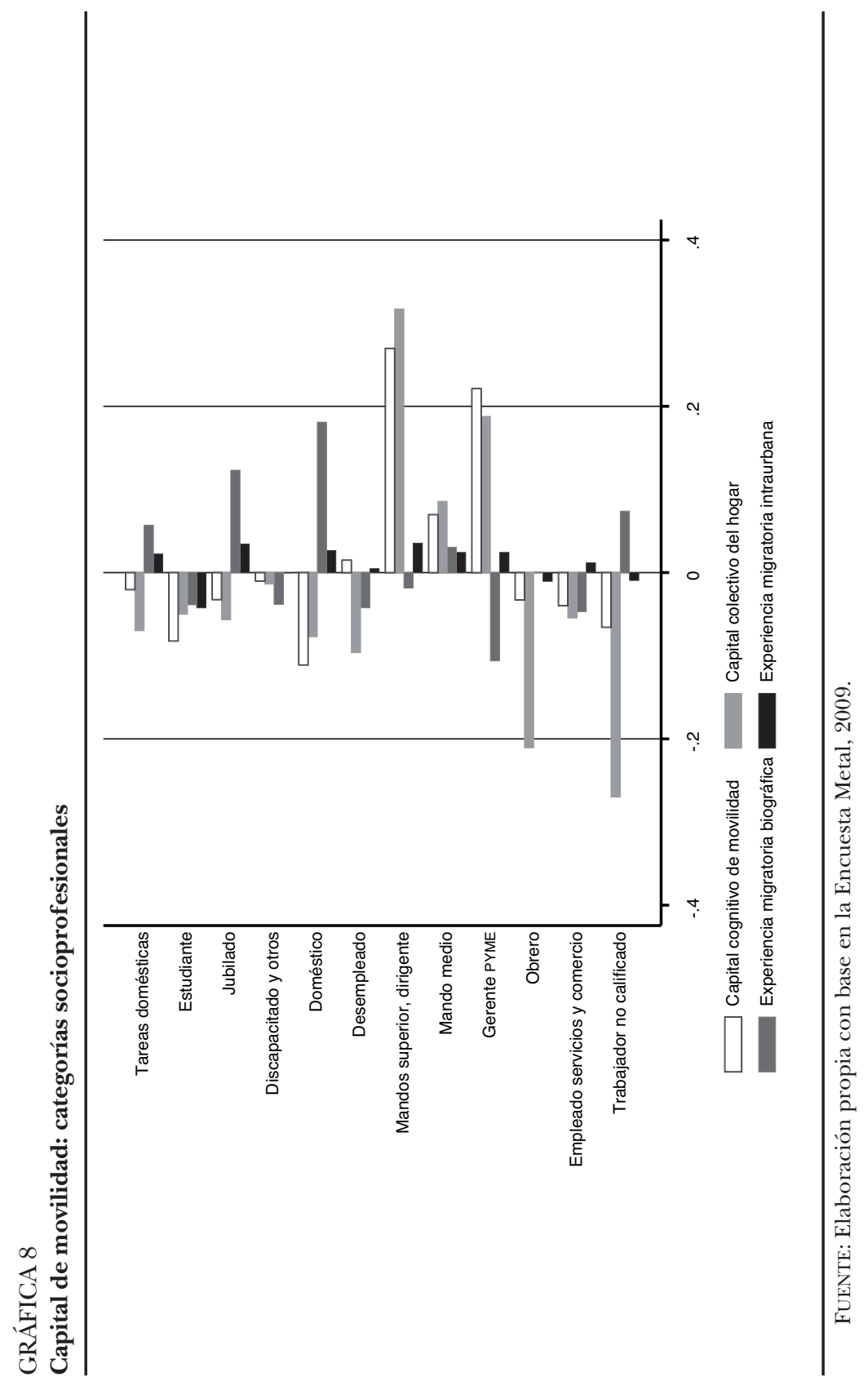


zamientos, con propósitos de "consumo" poco claros. Las clases superiores, los gerentes de PYME (pequeña y mediana empresa), la practican de manera más intensa. De este modo, es claro que existe un vínculo con el capital de movilidad, exceptuando a los empleados de los servicios y del comercio, que tienen mayor movilidad de la que sugieren sus capacidades. En esta categoría se encuentran también los trabajadores del sector informal o de actividades itinerantes. Los grados de multirresidencia, en cambio, se deslindan del capital de movilidad, ya que ésta se encuentra más ligada a la etapa de la vida que al estatus socioeconómico. Es más frecuente entre los mandos medios y los trabajadores no calificados. No se observa una relación clara entre las tasas de migración y el capital adquirido por la experiencia, a no ser por las clases altas que están vinculadas con la movilidad residencial intraurbana. Pero al entrar en pormenores, las estimaciones estadísticas no son robustas.

\section{La ubicación en la ciudad}

Numerosos estudios coinciden en demostrar que Santiago es una de las ciudades del continente más marcadas por la segregación (Rodríguez y Winchester, 1999; Arriagada y Rodríguez, 2004) debido en parte a que el crecimiento económico que sostuvo durante varias décadas incitó al agrupamiento residencial de las clases sociales en ascenso. Por ello la movilidad residencial y la cotidiana están ligadas a la diferenciación y a la movilidad socioeconómicas. La geografía del capital de movilidad confirma su contraste no tanto por la experiencia migratoria, sino por las capacidades del hogar y del capital cognitivo individual. Las diferencias son más tajantes para la primera que para la segunda. Esto es particularmente cierto en el caso de una comuna central en vías de rehabilitación y que presenta algunos aspectos de gentrificación (Contreras, 2006 y 2008,), Barrio Brasil-Yungay, que se sitúa en el promedio pero relativamente mejor posicionada en lo referente al capital cognitivo. El Volcán, en el sur de la periferia, es representativo de las clases relegadas en unidades habitacionales de interés social que funcionan como un confinamiento en una residencia alejada de las comodidades urbanas y del empleo. En el extremo opuesto, Los Trapenses (comuna de Lo Barnechea, al oriente de la ciudad) es un suburbio opulento, recientemente poblado por una élite que busca un marco de vida campestre, que toma la decisión y dispone de los medios para distanciarse de la 
ciudad. Los pormenores de esta geografía serían irrelevantes para el presente estudio si no fuera para confirmar la conclusión ya enunciada sobre la brecha entre el capital y la práctica. Los barrios centrales disponen de una dotación media de capital de movilidad, pero también sacan ventaja de su ubicación para solventar el grado de dificultad en los desplazamientos hacia los lugares de trabajo y de estudio, que aun así es aceptable. Los barrios periféricos localizados en la próspera zona norte deben pagar un precio por su lejanía, pero lo compensan con creces gracias a los medios de los que disponen, como automóviles y distribuidores viales. La discriminación más profunda se observa en los barrios marginados, de las cuales El Volcán es el ejemplo representativo: combinan una movilidad de trabajo necesaria y sumamente difícil (marcadamente positiva sobre la escala de los scores) con capacidades reducidas, muy negativas respecto al promedio y con dificultades de movilidad habitacional. La disyunción es total entre las posibilidades y la fuerte necesidad de desplazarse al trabajo, lo cual magnifica la discriminación por la ubicación (véase la gráfica 9).

Si la movilidad de trabajo es imperativa, la de consumo en cambio no lo es y se comporta con mayor flexibilidad. Su intensidad (frecuencia más distancia) sigue muy de cerca el déficit de accesibilidad a la ciudad reflejado en términos de capital: El Volcán muestra el índice más bajo, por mucho. Por el contrario, las zonas centrales gozan de un bono geográfico que rebasa sus capacidades individuales o domésticas, que presentan similitudes con las de las zonas mejor provistas y más alejadas (Chicureo-Colina al nororiente de la ciudad). De este modo, la práctica urbana combina las ventajas de la ubicación y las del capital de movilidad. El récord se lo llevan los lejanos habitantes de Los Trapenses, que deben salir de su sector para fines de consumo y uso de la ciudad. Las tasas de movilidad de los habitantes de El Volcán son también las más bajas de la muestra, y traducen en cifras el evidente confinamiento en una vivienda de interés social, que implica un elevado costo en accesibilidad a la ciudad.

\section{El testimonio de los habitantes: ensayo de tipología cualitativa simplificada}

Con el fin de percibir mejor las relaciones estadísticas entre el capital de movilidad, el lugar de residencia, el capital económico, pero igualmente el capital de educación, el capital de salud, etc., presentaremos 


\section{GRÁFICA 9}

\section{Geografía del capital de movilidad}

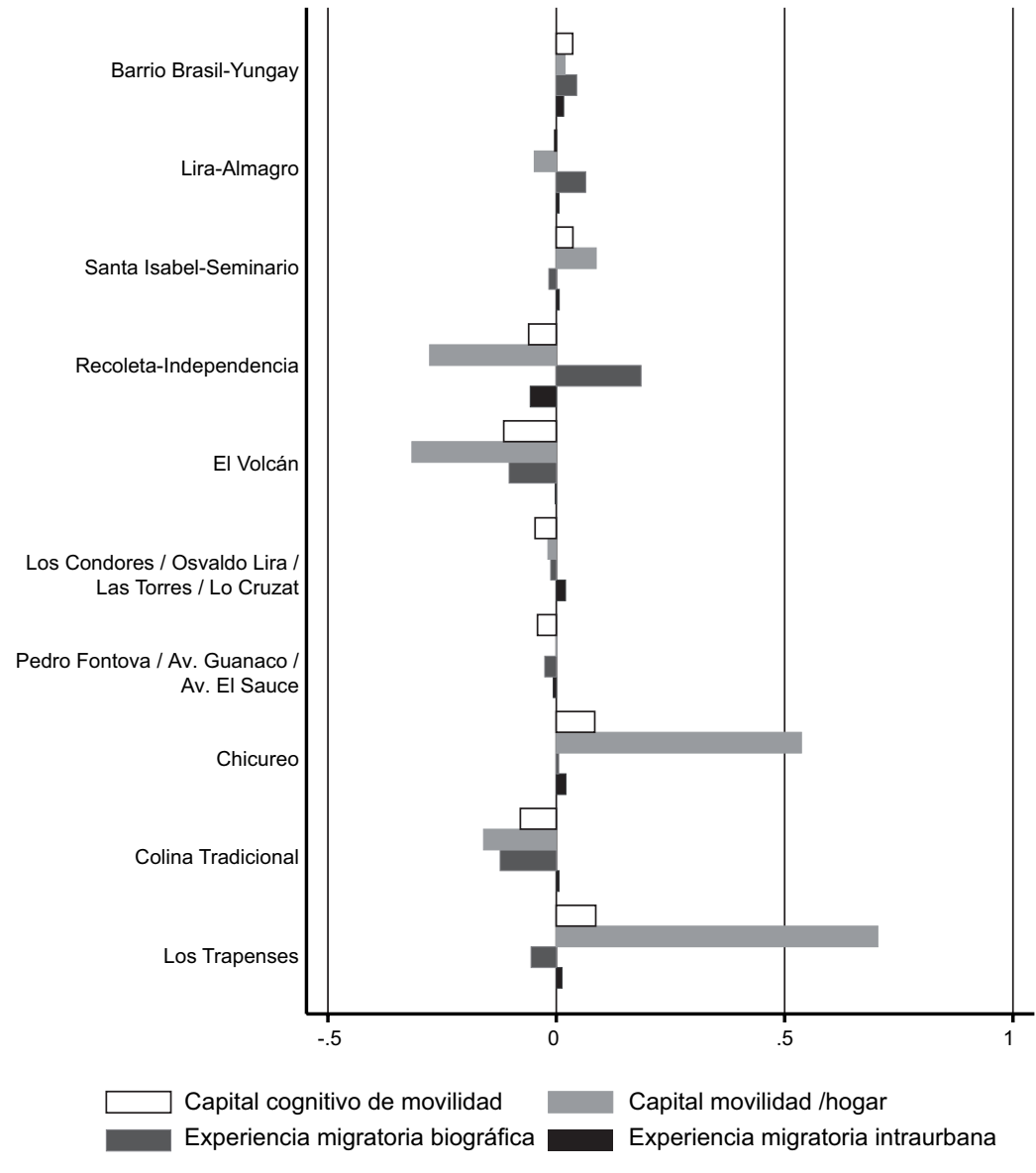

FUENTE: Elaboración propia con base en la Encuesta Metal, 2009. 
Delaunay, Fournier y Contreras, ¿ES POSIBLE MEDIR EL CAPITAL...?

cinco casos que ilustran la diversidad de situaciones. Fueron seleccionados de manera inductiva después de analizar las 84 entrevistas cualitativas. Estos perfiles no son representativos de la diversidad de nuestra muestra, pero evidencian ciertas asociaciones entre las diferentes formas de capitales.

\section{La acumulación de capital}

Camila, 30 años, soltera, forma parte de lo que podríamos llamar brevemente las "élites circulantes". Trabaja como ingeniera en una mina situada en el desierto de Atacama a unos 1700 kilómetros al norte de Santiago y se traslada varias veces por mes. Se le puede considerar una birresidente. Por cuestiones de trabajo ha viajado a Brasil, Australia e Italia, y además ha tenido la oportunidad de visitar Colombia, Ecuador y Costa Rica. Su decisión de vivir en el centro de Santiago corresponde a su gran accesibilidad, a la presencia de sitios artísticos, de moda o alternativos, a la cercanía de los almacenes de lujo, así como a las opciones culturales (bibliotecas, museos). Se desplaza en automóvil o a pie, pero no utiliza los transportes colectivos, que a ella le parecen demasiado restrictivos. Camila no conoce a sus vecinos en la medida en que su modo de vida se organiza como una red sin vínculo directo con el territorio local, arraigo que ella considera temporal. Ya que su salario es elevado, ella espera acumular un capital económico que le alcance para instalarse de manera permanente en Santiago. Viviendo en el centro, su movilidad potencial y efectiva es grande. Con un trabajo muy distante y bien remunerado (capital económico), aprovecha las actividades culturales del centro (capital de educación) y espera elaborar una tesis de doctorado (capital de educación). Sus estrategias se han orientado hacia un cúmulo de facetas diferentes de su capital global.

\section{Cautivo de una colonia marginada}

Antonio, 52 años, vive en el barrio periférico El Volcán, una de las zonas de interés social más estigmatizadas en toda la aglomeración de Santiago. Ha tenido que esperar 14 años para obtener la vivienda subsidiada que se le asignó y de la cual es propietario. Trabaja en una pequeña tienda de abarrotes familiar, pues una enfermedad le impide 
ejercer tareas físicas pesadas. Proviene de una familia de nueve hijos y ha ejercido toda una gama de oficios poco calificados a lo largo de su vida: obrero agrícola e industrial, albañil, comerciante ambulante, etc. Los problemas de drogas, de alcohol y de delincuencia marcan el ritmo cotidiano de su entorno, y él desearía vivir en otro lado. Nunca va al centro de Santiago y rara vez sale de su zona. Se está llevando a cabo un programa de renovación en el lugar por iniciativa del gobierno chileno, que busca destruir una parte de las viviendas de mala calidad y construir otras. El ministerio de vivienda ha propuesto a Antonio comprarle su vivienda, pero él se niega, pues calcula que el monto de la indemnización no compensaría todos los gastos que ha destinado a mejorarla. Su capacidad de movilidad, su capital económico, su capital de salud, su capital de educación y cultural son limitados. Al parecer, su suerte está ligada a los vaivenes de las políticas de vivienda, o bien al confinamiento residencial.

\section{Arraigo y movilidad de una cierta "clase media"}

Carmen, 45 años, cursó estudios universitarios para convertirse en nutrióloga pero nunca ejerció su profesión porque decidió ocuparse de su familia, y en particular de sus dos hijos de 7 y 14 años de edad. Desde que contrajo matrimonio, hace 20 años, vive con su marido en un conjunto residencial cerrado, con acceso controlado (condominio), conformado por varias torres y ubicado en el centro de Santiago. Se desplaza a pie en su colonia; a veces toma el metro pero nunca los autobuses, pues el sistema le parece muy complicado. No sabe conducir y parece depender de su marido o de un tercero para llegar a ciertos lugares inaccesibles. Además se desplaza muy poco dentro de los límites de Santiago. Vivir en la periferia le parece algo imposible, ya que no podría acceder a todos los servicios disponibles en el centro. En cambio sus hijos hacen largos trayectos para ir a una escuela privada muy reconocida (Liceo Alemán) y para tomar cursos de piano y de violín. También habla de la Clínica Santa María, una clínica privada en donde se ha atendido toda la familia. Nunca va hacia la zona sur de Santiago, popular, en donde reside una parte de su familia, y se traslada de vez en cuando a las comunas ricas del noreste en donde viven algunos conocidos, entre ellos los padres de los amigos de sus hijos. La familia desea aumentar los capitales de los dos hijos dentro de una estrategia de promoción social: el capital de movilidad, el capital de 
Delaunay, Fournier y Contreras, ¿ES POSIBLE MEDIR EL CAPITAL...?

educación (desplazamientos hacia la escuela), el capital de salud (clínica reconocida), el capital cultural (cursos de música) y el capital social (contactos con familias de las colonias adineradas).

\section{Las limitantes de vivir en la periferia}

Liliana, 22 años, vive con su madre y con su hermana en un barrio muy popular que en un principio fue autoconstruido y se ha consolidado poco a poco (Villa Esperanza), en la comuna de Huechuraba, al norte de Santiago. La particularidad de esta zona es que está rodeada de fraccionamientos en donde residen categorías medias y altas. El espacio vital de Liliana tiene más la forma de una red dispersa en varios puntos de Santiago que la de un territorio local continuo alrededor de su vivienda. Ella declara que pasa más tiempo en los transportes que con su familia. Trabaja como vendedora en un comercio del centro de Santiago y asiste a cursos vespertinos en una universidad técnica pública, aledaña a su zona de trabajo. Sale de su vivienda cada mañana alrededor de las 6:30 para volver cerca de las 23:30, ya que pasa al menos una hora y media en el trayecto (autobús, metro y marcha a pie). Explica que no aprovecha realmente los servicios u oportunidades del centro debido a que su agenda está muy saturada. Tan pronto como termina su jornada de cursos debe emprender el regreso a casa, pues los autobuses escasean por la noche; después de media noche ya no hay ninguno que vaya hacia su barrio, en donde muchos de los habitantes poseen automóvil particular. El fin de semana imparte clases privadas de matemáticas y de química a los hijos de las familias que viven en los fraccionamientos aledaños más adinerados. Le gusta ver a sus amigos los sábados en un parque del centro. Había conseguido un empleo mucho más conveniente para su formación en un laboratorio de análisis, pero no podía vivir en una ubicación, estudiar en otra y trabajar en una más. El arreglo consistió en tener dos actividades cercanas entre ellas (trabajo y estudio) en detrimento de un empleo más interesante para su formación profesional. Su capital de movilidad es muy considerable mientras que su origen modesto limita su capital económico, social y cultural. 


\section{La reproducción del capital}

Isabel, 42 años, vive en un fraccionamiento muy lujoso y alejado en la periferia norte (Los Trapenses), a una hora en automóvil del centro de Santiago. Posee un título de ingeniero comercial que obtuvo en la prestigiosa Universidad Católica de Chile, pero no ejerce su profesión para poder ocuparse de sus dos hijos de 15 y 17 años: todas las mañanas y todas las tardes invierte una hora y cuarto en llevarlos o traerlos entre la casa y la escuela. Define su papel principal en la familia como "chofer", ya que dispone de una empleada de tiempo completo para las tareas domésticas. Su marido es médico y tiene dos empleos en dos hospitales: uno público y otro privado. Disponen de dos automóviles y utilizan las vías rápidas de paga. No se imaginan utilizando los transportes colectivos, que además son muy escasos en su zona. Isabel va a hacer las compras y a ver a sus amigas en los centros comerciales de lujo de las comunas adineradas del noreste, en donde viven todos sus parientes y sus suegros. Salen de viaje varias veces al año al extranjero, hacia América Latina y Europa, pero también hacia Estados Unidos, y han ido a China. Su capital de movilidad imprime valor a su capital económico (el marido puede trabajar en dos hospitales utilizando las vías rápidas) y a su capital de educación (escolarización de los hijos en escuelas de prestigio). Además pueden vivir en un fraccionamiento provisto de muchas áreas verdes, socialmente muy selectivo, y en el cual se puede cultivar la exclusividad social (capital social).

En estos cinco casos se pueden observar los vínculos entre las diferentes formas de capital. Se advierten niveles de movilidad muy heterogéneos en las periferias que corresponden a posiciones sociales diferentes. Si bien los habitantes adinerados de las periferias pueden pasar tanto tiempo en los transportes como los residentes de otras categorías sociales, tienen acceso a mayores recursos que a final de cuentas les permiten volver confortable su posición social. Por lo tanto la distancia no impone las mismas restricciones para todos: algunos pueden prácticamente dejar de preocuparse por ella (Isabel), mientras que otros la padecen como una gran carencia (Antonio), y otros más se ubican en una posición intermedia (Liliana). La misma comprobación se puede hacer respecto al centro: los habitantes que aprovechan al máximo las ventajas del centro (Camila) son quienes poseen un capital de movilidad suficientemente grande para hacer fructificar las otras formas de capital, mientras que otros sólo pueden aprovechar esto de manera parcial (Carmen) o muy poco. 
Delaunay, Fournier y Contreras, ¿ES POSIBLE MEDIR EL CAPITAL...?

\section{Conclusiones}

Se espera haber conseguido dos resultados por medio de este trabajo: el primero es de orden metodológico y pretende, como fruto del esfuerzo realizado para medir el capital de movilidad, evaluar la operatividad de dicho concepto. El segundo desafío es de orden empírico, ya que se documentó con la explotación de una encuesta dedicada al estudio de la movilidad y diseñada para describir de la mejor manera posible las prácticas en función de su localización en la zona metropolitana, poniendo énfasis en la selección de las zonas clave.

A pesar del rigor que hemos aplicado a la definición estadística de los diferentes componentes de la capacidad para desplazarse, hace falta debatir las alternativas que se tomaron, en parte inspiradas por consideraciones teóricas pero también incluidas con amplitud en las estadísticas disponibles. Incluir por ejemplo los desplazamientos culturales para complementar la medición de la capacidad intelectual $\mathrm{u}$ organizativa para desplazarse sólo es una opción entre otras posibles. Para circunscribir un concepto complejo ha sido necesario descomponerlo. No todos los elementos presentan el mismo grado de pertinencia para cada forma de movilidad, incluso por zona. La experiencia migratoria basada en las trayectorias residenciales aporta muy poco a la comprensión de los traslados de trabajo o de la movilidad de consumo, al contrario de lo que ocurre con el capital cognitivo o el equipamiento del hogar. Con carácter exploratorio, la construcción de los índices tiene la ventaja de focalizarse en prácticas más específicas. Hemos intentado eludir los riesgos de una definición tautológica del capital al no mezclar los ladrillos que se utilizan para construirlo con los que componen las prácticas, las cuales a su vez se distinguen de los factores de discriminación (sexo, edad, csP y zona o barrio). La separación estadística de los tres objetos se ha respaldado en el uso de los ejes factoriales del análisis por componentes principales eliminando las colinealidades a costa del alisado de la información. El resultado es una estimación satisfactoria, aunque perfectible, de diferentes formas del capital de movilidad.

El alcance empírico del análisis, solamente esbozado en este trabajo, ha tenido que conciliarse con los datos de la encuesta Metal de acuerdo con un protocolo construido para tres capitales latinoamericanas (Bogotá, São Paulo y Santiago). En la práctica la mayor dificultad ha sido lidiar con los numerosos aspectos de la movilidad y su difícil medición al aplicarla a grupos específicos. En algún punto las 
comparaciones parecerían tener más cabida en una monografía: un capital determinado contra un tipo de movilidad para una población específica. Pero para un análisis que se enfoque en los comportamientos la representatividad de la muestra es menos crucial (Riandey, 1990). Se respira a veces la sensación de que este pronunciamiento por el capital de movilidad aporta poco, ya que examina las relaciones entre la movilidad y la educación, el equipamiento del hogar, la moda estadística de transporte, el estatus de ocupación de la vivienda, etc., que son los ítems habituales de los estudios de la movilidad urbana. Sin embargo esto no ocurre cuando se confronta un resultado empírico inhabitual. Al cuantificar de manera independiente la capacidad para trasladarse y la práctica efectiva, la medición de las discriminaciones ha cobrado una nueva dimensión: ya no son solamente los niveles o el costo de movilidad lo que hace la diferencia, sino sobre todo la brecha entre una práctica obligada y la capacidad o aptitud para instrumentarla. La brecha ampliada de este modo resalta considerablemente lo que representa para algunos la necesidad de desplazarse en una metrópoli marcada por una segregación tan grande como la que se ha presentado. Las diferencias entre las prácticas no son otra cosa que la parte emergente de la discriminación y del precio de la segregación, retomando en esto la noción económica de capital que también acumula deficiencias. Los testimonios de algunos habitantes evocan y dan cuerpo a esta conclusión estadística. El relegamiento a los barrios pobres por falta de capital de movilidad cotidiana y residencial se encuentra en uno de sus extremos. Pero en el otro, el desclasamiento profesional de una mujer casada de las zonas ricas, prisionera de una movilidad elegida para conservar una exclusividad muy valorizada, muestra otro encierro en una práctica y una lógica sociales del territorio.

\section{Bibliografía}

Arriagada, C. y J. Rodríguez (2004), "Segregación residencial en la ciudad latinoamericana”, Eure, vol. 30, núm. 89, pp. 5-24.

Bell, M. y G. Ward (2000), "Comparing Temporary Mobility with Permanent Migration”, Tourism Geographies, vol. 2, núm. 1, pp. 87-107.

Booysen, F., S. van der Berg, R. Burger, M.V. Maltitz y G.D. Rand (2008), "Using an Asset Index to Assess Trends in Poverty in Seven Sub-Saharan African Countries”, World Development, vol. 36, núm. 6, pp. 1113-1130.

Borsdorf, A. y R. Hidalgo (2008), "New Dimensions of Social Exclusion in 
Delaunay, Fournier y Contreras, ¿ES POSIBLE MEDIR EL CAPITAL...?

Latin America: From Gated Communities to Gated Cities, the Case of Santiago de Chile”, Land Use Policy, núm. 25, pp. 153-160.

Bourdieu, P. (1979), La distinction, critique sociale du jugement, París, Les Editions de Minuit.

Cáceres, G. y F. Sabatini (2004), Barrios cerrados en Santiago de Chile entre la exclusión y la integración residencial, Santiago de Chile, Lincoln Institute of Land Policy / Pontificia Universidad Católica de Chile.

Contreras, Y. (2006), "La Commune de Santiago du Chili: une nouvelle option résidentielle pour la ville”, en H. Rivière d'Arc y M. Memoli (coords.), Le pari urbain en Amérique Latine: vivore dans le centre des villes, París, A. Colin, pp. 171-184.

Contreras, Y. (2008), La gestión inmobiliaria en el Centro de Santiago de Chile: ¿el traje a la medida del mercado inmobiliario?, Santiago de Chile, Instituto de Estudios Urbanos y Territoriales, Pontificia Universidad Católica de Chile.

Delaunay, D. (2007), "Relaciones entre pobreza, migración y movilidad: dimensiones territorial y contextual”, Notas de Población, vol. 84, núm. 34, pp. 87-130.

Delaunay, D. (2010), “Mobilités, ségrégations résidentielles et bonus démographique dans la zone métropolitaine de Santiago du Chili”, Tiers Monde, núm. 201, pp. 48-87.

Donzelot, J. y O. Mongin (2004), "La ville à trois vitesses: gentrification, relégation, périurbanisation”, Esprit, núm. 303, pp. 14-39.

Figueroa, O. (2005), "Transporte urbano y globalización. Políticas y efectos en América latina”, Eure, vol. 31, núm. 94, pp. 41-53.

Fuentes, L. y C. Sierralta (2005), "Santiago de Chile, ejemplo de una reestructuracion capitalista global”, Eure, vol. 30, núm. 91, pp. 1-23.

Hidalgo, R. (2007), “'Se acabó el suelo en la gran ciudad? Las nuevas periferias metropolitanas de la vivienda social en Santiago de Chile”, Eure, vol. 33, núm. 98, pp. 57-75.

Jouffe, Y. (2010), "La paradoxale mobilité des travailleurs précaires: vers de nouvelles inégalités", en M.H. Massot (coord.), Mobilités et modes de vie métropolitains: les intelligences du quotidien, París, Univesité Paris-Est, pp. 139-154.

Kaufmann, V. y C. Jemelin (2010), "La motilité, une forme de capital permettant d'éviter les irréversibilités socio-spatiales?”, en M.H. Massot (coord.), Mobilités et modes de vie métropolitains: les intelligences du quotidien, París, Univesité Paris-Est, pp. 83-91.

Korsu, E. (2010), "La proximité domicile-travail dans les choix résidentielles et professionnels de l’individu hyper-moderne”, en M.H. Massot (coord.), Mobilités et modes de vie metropolitaines. Les intelligences du quotidien, París, L'oeil d'or.

Le Breton, E. (2005), Bouger pour s'en sortir, París, Armand Colin.

Mattos, C. de y R. Hidalgo (coords.) (2007), Movilidad espacial y reconfiguración metropolitana, Santiago de Chile, Instituto de Estudios Urbanos, Pontificia 
Universidad Católica de Chile (Geolibros).

Montezuma, R. (2003), "Ciudad y transporte. La movilidad urbana", en M. Balbo (coord.), La ciudad inclusiva, Santiago de Chile, pp. 175-191 (Cuadernos de la CEPAL, 88).

Orfeuil, J.P. (coord.) (2004), Transports, pauvretés, exclusions, pouvoir bouger pour s'en sortir, París, Editions de l'Aube.

Paquette, C. (2000), "Santiago du Chili: des choix résidentiels très réduits pour les plus modestes", en F. Dureau, V. Dupont, E. Lelièvre et al., Métropoles en mouvement: une comparaison internationale, París, Economica, pp. 211-218.

Riandey, B. (1990), "L'optimisation des plans de sondage pour les mesures différentielles", Population (French Edition), vol. 6, núm. 45, pp. 993-1012.

Rodríguez, J. (2008), “Movilidad cotidiana, desigualdad social y segregación residencial en cuatro metrópolis de América Latina”, Eure, vol. 34, núm. 103, pp. 49-71.

Rodríguez, C. y O. Figueroa (2008), "Redes e infraestructuras de transporte en la conformacion de la nueva Área Metropolitana de Santiago", en Actas del XIII Congreso Latinoamericano de Transporte Público y Urbano, Lima, CIDATT.

Rodríguez, A. y A. Sugranyes (2004), Los con techo, Un desafío para la política de vivienda social, Santiago de Chile, Ediciones Sur.

Rodríguez, A. y L. Winchester (1999), Santiago de Chile: una ciudad fragmentada, Birmingham, University of Birmingham, pp. 115-136.

Sabatini, F. e I. Brain (2008), "La segregación, los guetos y la integración social urbana: mitos y claves”, Eure, vol. 27, núm. 103, pp. 5-26.

Winchester, L. (2008), "La dimensión económica de la pobreza y precariedad urbana en las ciudades latinoamericanas. Implicaciones para las políticas del hábitat”, Eure, vol. 34, núm. 103, pp. 27-47.

\section{Acerca de los autores}

Daniel Delaunay es demógrafo y economista. Es Director de Investigación Emérito del Institut de Recherche pour le Developpement (IRD). Su laboratorio es UMR 201 "Desarrollo y Sociedades", Universidad de París 1 Panthéon-Sorbonne e IRD. Sus investigaciones han versado sobre los fenómenos de la migración, la movilidad y la recomposición urbana, y las configuraciones espaciales de los fenómenos demográficos. Ha desarrollado estos temas en Senegal, Brasil, Ecuador, México, Chile, y más recientemente en Burkina Faso y Níger. Algunas de sus publicaciones están disponibles en: <http://www.documentation.ird.fr>. 
Jean-Marc Fournier es profesor de Geografía Social en la Universidad de Caen, Normandía (Francia); es miembro de la unidad "Espacios y Sociedades" del Centro Nacional de la Investigación Científica (CNRS). Sus investigaciones han versado sobre los cambios urbanos y sociales en Venezuela, en México y más recientemente en Chile. Se ha enfocado en el estudio de las desigualdades sociales y de las relaciones de poder en la producción del espacio urbano.

Yasna Contreras Gatica es geógrafa y doctora en Arquitectura y Estudios Urbanos por la Pontificia Universidad Católica de Chile; es doctora en Geografía por la Universidad de Poitiers. Actualmente es profesora asistente del Departamento de Geografía de la FAU, Universidad de Chile. Se especializa en gentrificación y movilidad residencial. Dirige un Proyecto Fondecyt (11121241) sobre mercado de arriendo y trayectorias residenciales de los precarios urbanos del centro de Santiago e Iquique. 
